\title{
Development of SNP markers for genes of the phenylpropanoid pathway and their association to kernel and malting traits in barley
}

\author{
Manuela Peukert, Stephan Weise, Marion S Röder ${ }^{*}$ and Inge E Matthies
}

\begin{abstract}
Background: Flavonoids are an important class of secondary compounds in angiosperms. Next to certain biological functions in plants, they play a role in the brewing process and have an effect on taste, color and aroma of beer. The aim of this study was to reveal the haplotype diversity of candidate genes involved in the phenylpropanoid biosynthesis pathway in cultivated barley varieties (Hordeum vulgare L.) and to determine associations to kernel and malting quality parameters.

Results: Five genes encoding phenylalanine ammonia-lyase (PAL), cinnamate 4-hydroxylase (C4H), chalcone synthase (CHS), flavanone 3-hydroxylase (F3H) and dihydroflavonol reductase (DFR) of the phenylpropanoid biosynthesis pathway were partially resequenced in 16 diverse barley reference genotypes. Their localization in the barley genome, their genetic structure, and their genetic variation e.g. single nucleotide polymorphism (SNP) and Insertion/Deletion (InDel) patterns were revealed. In total, 130 SNPs and seven InDels were detected. Of these, 21 polymorphisms were converted into high-throughput pyrosequencing markers. The resulting SNP and haplotype patterns were used to calculate associations with kernel and malting quality parameters.

Conclusions: SNP patterns were found to be highly variable for the investigated genes. The developed high-throughput markers are applicable for assessing the genetic variability and for the determination of haplotype patterns in a set of barley accessions. The candidate genes PAL, C4H and F3H were shown to be associated to several malting properties like glassiness (PAL), viscosity (C4H) or to final attenuation (F3H).
\end{abstract}

Keywords: Phenylpropanoids, Barley, SNP, Haplotype, Associations, Malting quality parameters

\section{Background}

In 2010, Germany ranked $1^{\text {st }}$ with $10,412,100$ tons of global barley production followed by France, Ukraine and Canada [1]. For human consumption barley is mostly supplied to brewing and distilling [2], but recently, the interest in barley as a functional food increased due to its content of beneficial components for the human diet [3-6]. Thus, important breeding aims are to enhance the malting quality next to the improvement of yield components.

All genes studied here are part of the phenylpropanoid pathway, coding especially for enzymes of the flavonoid synthesis pathway. Their gene products represent the mostly abundant group of secondary metabolites in angiosperms

\footnotetext{
* Correspondence: roder@ipk-gatersleben.de

Leibniz-Institute of Plant Genetics and Crop Plant Research (IPK), OT

Gatersleben, Corrensstr. 3, 06466 Stadt Seeland, Germany
}

[7]. A wide range of phenylpropanoids is abundant in the barley grain, such as phenolic acids and flavanols (such as proanthocyanidins) [3]. The heterogeneous group of flavonoids is derived from phenylalanine and malonyl-CoA. Several classes of them can be differentiated by the oxidation states of the carbon atoms $\mathrm{C}-2, \mathrm{C}-3$ and $\mathrm{C}-4$ in the oxygenic heterocycle, and they are mainly stored in plant vacuoles. The corresponding enzymes of biosynthesis are assumed to form membrane-associated complexes at the cytoplasmatic oriented side of the rough endoplasmatic reticulum [8]. A general overview of the biosynthetic pathway is given in Figure 1. Starting from the general phenylpropanoid metabolism phenylalanine is deaminated to cinnamate catalyzed by the phenylalanine ammonia-lyase (PAL). The cinnamate 4-hydroxylase $(\mathrm{C} 4 \mathrm{H})$ hydroxylates the product to coumarate, which is then converted to 4-coumaroyl 


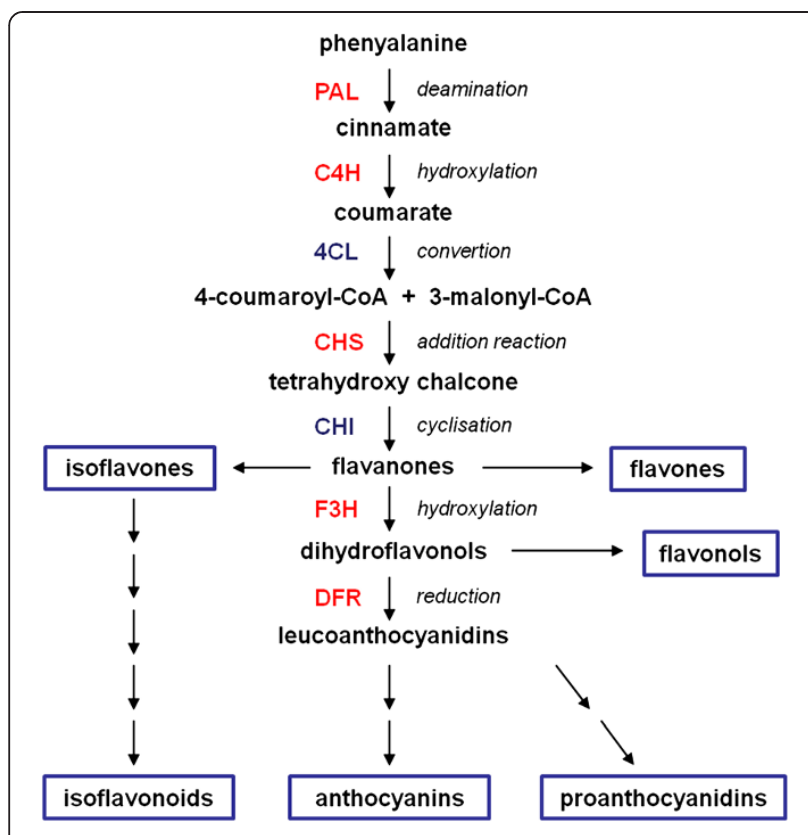

Figure 1 Biosynthetic pathway of flavonoids with the investigated genes labeled in red. Abbreviations of the enzymes are: PAL - phenylalanine ammonia-lyase; $\mathrm{C} 4 \mathrm{H}$ - cinnamate 4-hydroxylase; $4 \mathrm{CL}$ - 4-coumaroyl-CoA ligase; CHS - chalcone synthase; $\mathrm{CH}$ - chalcone isomerase; $\mathrm{F3H}$ - flavanone 3-hydroxylase; DFR - dihydroflavonol reductase.

4-coumaroyl-CoA is added to three molecules malonylCoA to form tetrahydroxy chalcone, catalyzed by the chalcone synthase (CHS). The following steps to the formation of anthocyanins include the chalcone isomerase $(\mathrm{CHI})$ catalyzed cyclization of naringenin chalcone to naringenin (flavanone), the production of dihydroflavonols by the flavanone 3-hydroxylase $(\mathrm{F} 3 \mathrm{H})$, and the reduction of them to leucoanthocyanidins by the dihydroflavonol reductase (DFR) [9]. Other branches of the central biosynthesis lead to the formation of flavones, isoflavonoids or flavonols.

The high structural diversity of flavonoids is related to many biological functions: Anthocyanins are plant pigments and serve as attractants for pollinators and seed dispersers. Others flavonoids are known to exhibit repellent functions against herbivorous insects [10]. In form of phytoalexines they possess antimicrobial effects. Abiotic stress factors such as salt, low temperatures or high light intensities enhance the flavonoid content in plant or grain tissues [11], which is related to the antioxidant capacities of these compounds. The property of phenols to act as scavengers of free radicals such as reactive oxygen species [6] constitutes to the importance of flavonoids as pharmacological substances effecting cancer, cardiovascular and age-related degenerative diseases [5,12]. The antioxidant effects play a role during the malting and brewing process as well, where barley flavonoids have an impact on taste, color and foam stability of the beer [5,6]. A high content of proanthocyanidins causes precipitation of proteins in beer resulting in formation of colloidal haze [13]. Proanthocyanidine free barley accessions possess same malting properties and show better chemical and physical stability of the beer, but a negative influence on the flavor stability was observed [14]. Additionally, the use of barley accessions with a high content of condensed proanthocyanidins (tannins) lead to a more intensive coloration during the brewing process.

The relationship between genetic diversity and phenotypic performance is assessed by association studies. Source for these investigations are single nucleotide polymorphisms (SNP) and the combination of various SNPs within one gene to haplotypes. Several association studies for specific candidate genes were performed in barley [15-21]. Until now, no genes from the secondary phenylpropanoid pathway were investigated for their impact on malting traits.

The aim of the present study was (i) the assessment of allelic diversity of genes representing the phenylpropanoid pathway in barley and (ii) the determination of significant associations of the detected single nucleotide polymorphisms (SNPs) or their resulting haplotypes with kernel and malting quality parameters.

\section{Results and discussion}

\section{SNP Patterns and marker development}

Five genes of the phenylpropanoid metabolic pathway were investigated for their abundance of polymorphisms and for associations to kernel and malting quality parameters, which will be further described.

A high variability of SNP frequency in the investigated fragments of the candidate genes was observed (Table 1). The highest number of detected SNPs was observed in one fragment of the PAL encoding gene. For PAL_2 a frequency of $58.8 \mathrm{SNPs} / \mathrm{kb}$ was found. Less SNPs were detected in the gene fragment CHS_GM290 with a density of $1.5 \mathrm{SNPs} / \mathrm{kb}$. This high polymorphic variability was also described in the findings of Bundock et al., Kanazin et al. and Rostoks et al. [22-24]. Additionally, Matthies et al. [19-21] revealed highly different SNP-frequencies in candidate genes of the C-metabolism in barley.

\section{Phenylalanine ammonia-lyase (PAL)}

Two fragments of the gene encoding $P A L$ were amplified resulting in a total of $877 \mathrm{bp}$ of the sequenced exonic region. Both fragments have an overlapping identical region of 322 bp. Within this area a completely different SNP pattern was observed with only two identical SNPs between both sequenced fragments (SNP 1 and SNP 2 of PAL_1 with SNPs 16 and 17 of PAL_2, illustrated in Figure 2). Thus, both fragments must belong to different gene copies of the PAL gene family. Kervinen et al. [25] also observed at least five copies of a PAL gene family in barley. The consensus sequences for 
Table 1 Genetic structure of all investigated candidate gene fragments of the phenylpropanoid pathway after resequencing and aligning of 16 barley reference genotypes

\begin{tabular}{|c|c|c|c|c|c|c|c|}
\hline Gene fragment & Fragment size [bp] & Exon size [bp] & Intron size [bp] & 3' UTR [bp] & No. of InDels & No. of SNPs & SNP frequency per kb \\
\hline$\overline{\text { PAL_1 }}$ & 604 & 604 & - & - & 0 & 5 & 8.3 \\
\hline PAL_2 & 595 & 595 & - & - & 0 & 35 & 58.8 \\
\hline $\mathrm{C}_{4} \mathrm{H}_{-} 1$ & 495 & 46 & - & 449 & 0 & 4 & 8.1 \\
\hline $\mathrm{C} 4 \mathrm{H} \_4$ & 681 & 681 & - & - & 0 & 2 & 2.9 \\
\hline CHS_1 & 252 & 252 & - & - & 0 & 0 & 0 \\
\hline CHS_2 & 255 & 255 & - & - & 0 & 0 & 0 \\
\hline CHS_3 & 369 & 369 & - & - & 0 & 0 & 0 \\
\hline CHS_GM0287 & 321 & 235 & - & 86 & 0 & 11 & 34.3 \\
\hline CHS_GM0290 & 661 & 661 & - & - & 0 & 1 & 1.5 \\
\hline CHS_GM0293 & 474 & 474 & - & - & 0 & 17 & 35.9 \\
\hline F3H_1 & 796 & 199 & 597 & - & 4 & 48 & 60.4 \\
\hline F3H_GM022 & 544 & 389 & 109 & 46 & 2 & 3 & 5.5 \\
\hline DFR_1 & 618 & 428 & 105 & 85 & 0 & 1 & 1.6 \\
\hline DFR_3 & 564 & 459 & 105 & - & 1 & 3 & 5.3 \\
\hline DFR_4 & 915 & 759 & 105 & 51 & 1 & 3 & 3.3 \\
\hline
\end{tabular}

both fragments generated from 16 reference genotypes were 99\% identical to the cDNA clone AB367438 [26].

Five SNPs were identified in the $604 \mathrm{bp}$ long fragment PAL_1. All represent silent mutations and defined three haplotypes (Additional file 1). Except of PAL_1_SNP2 all SNPs were converted into pyrosequencing markers for the use in high-throughput genotyping (Table 2). For SNP2 no distinct alleles were observed, which can be explained by non-specific annealing of the pyrosequencing primer to different $P A L$ gene family members. The second gene fragment PAL_2 consists of 595 nucleotides with 35 detected SNPs in a set of 16 reference genotypes. Two of these detected SNPs were missense mutations. SNP2 causes an amino acid exchange of methionin (ATG) into isoleucine (ATA) and SNP24 leads to an exchange of leucin (CTC) into phenylalanine (TTC). Five out of 35

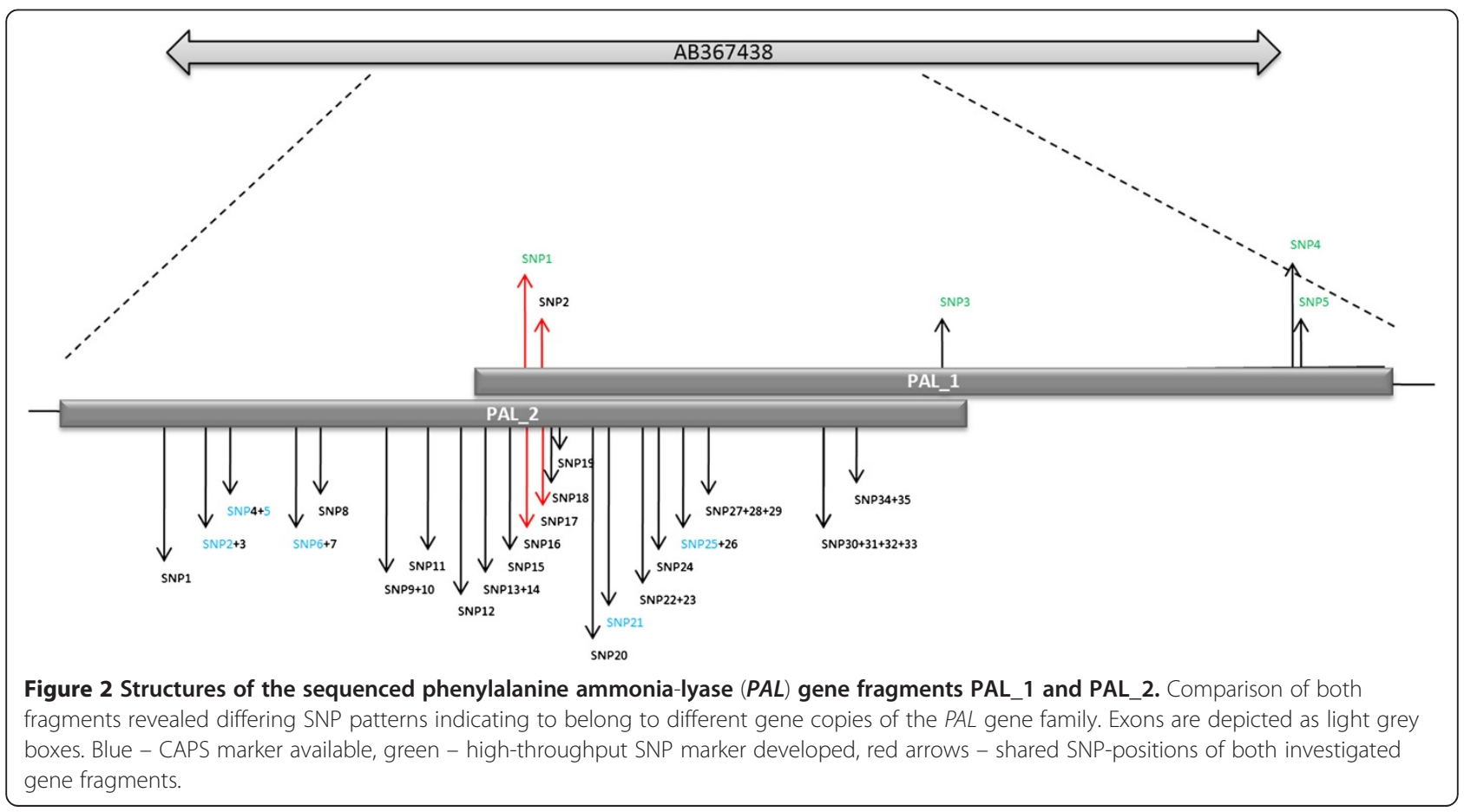


Table 2 SNP and haplotype pattern of the phenylalanine ammonia-lyase (PAL) encoding gene, assessed by pyrosequencing assays for the SNPs 1, 3, 4 and 5 in a set of 190 European barley cultivars and the 6-rowed mapping parents Steptoe and Morex

\begin{tabular}{|c|c|c|c|c|c|c|c|c|c|}
\hline \multirow[t]{2}{*}{ Haplotypes } & \multicolumn{4}{|c|}{ SNPs from 5 ' to $3^{\prime}$} & \multicolumn{4}{|c|}{$\begin{array}{l}\text { Haplotype frequency (No. of cultivars) } \\
\text { according row number and growth habit }\end{array}$} & \multirow[t]{2}{*}{$\begin{array}{l}\text { Haplotype frequency } \\
\text { (No. of cultivars) }\end{array}$} \\
\hline & SNP1 & SNP3 & SNP4 & SNP5 & $2 r-S$ & $6 r-S$ & $2 r-W$ & $6 r-W$ & \\
\hline PAL_H1 & A (Pro) & C (Leu) & A (Arg) & G (Ala) & 80 & - & 38 & 3 & 121 \\
\hline PAL_H2 & C (Pro) & C (Leu) & A (Arg) & G (Ala) & 13 & 1 & 3 & 25 & 42 \\
\hline PAL_H3 & C (Pro) & $\mathrm{T}(\mathrm{Leu})$ & $\mathrm{T}($ Arg) & A (Ala) & 1 & 1 & 20 & 6 & 28 \\
\hline Unknown & \multicolumn{4}{|c|}{ Missing SNP information } & - & - & - & 1 & 1 \\
\hline Total & & & & & 94 & 2 & 61 & 35 & 192 \\
\hline
\end{tabular}

All SNP markers shown in $5^{\prime}$ to $3^{\prime}$ direction are localized in the exonic region. Coding amino acids are given in brackets. $S=S p r i n g, W=$ Winter, $2 \mathrm{r}=$ two-rowed, 6r $=$ six-rowed.

detected SNPs were converted into CAPS markers (Figure 2). Despite of the high SNP frequency (58.8 SNP/kb) a low number of haplotypes is stated due to linkage (Additional file 2). Two haplotypes (PAL_2_H3 and H4) possessed completely different SNP patterns while five haplotypes differed only in one of six SNPs (Additional file 2).

\section{Cinnamate 4-hydroxylase (C4H)}

The two resequenced gene fragments from $\mathrm{C} 4 \mathrm{H}$ showed $100 \%$ identity to cDNA AK250541 [27]. The first fragment $\mathrm{C} 4 \mathrm{H} \_4$ with $681 \mathrm{bp}$ is located near the 5' end whereas $\mathrm{C} 4 \mathrm{H} \_1$ consists of $46 \mathrm{bp}$ exonic sequence followed by 449 bp 3' UTR. Both fragments have no introns. Altogether, six SNPs were detected and four of them were converted into pyrosequencing markers (Additional file 3). CAPS assays for two of the SNPmarkers are also available (Figure 3 ). The exonic polymorphisms C4H_4_SNP1 and C4H_4_SNP2 are silent mutations. Four SNPs found in $\mathrm{C}_{4} \mathrm{H}_{-} 1$ are localized in the 3'UTR.

Genotyping for C4H_1 was performed with 190 barley cultivars using all four pyrosequencing markers. Three haplotypes were determined (Table 3 ).

\section{Chalcon synthase (CHS)}

It is known that the CHS in $H$. vulgare represents a gene family [28]. Six fragments were amplified. The genomic sequences of CHS_1, CHS_2 and CHS_3 revealed no polymorphisms within the 16 reference genotypes. Two fragments CHS_GM290 and CHS_GM293 shared identical regions of the cDNA clone Y09233 [28], and comparable to the findings for the $P A L$ gene fragments different SNP patterns were observed (Additional file 4). Therefore it is assumed that both fragments belong to different gene copies of the CHS gene family. For CHS_GM290 a 661 bp exonic sequence containing only one SNP was detected, which was converted into a pyrosequencing marker. This

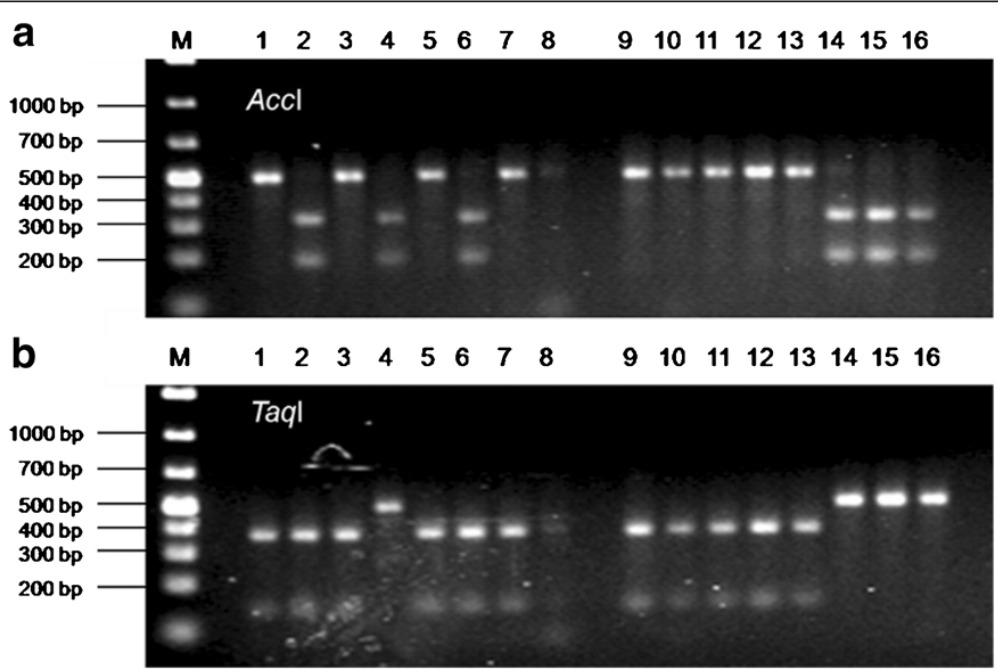

Figure 3 CAPS assays for SNP 1 (a) and SNP 4 (b) of the $\mathbf{C} 4 \mathbf{H} \_1$ gene fragment. The restriction pattern is derived by using the enzymes Accl for SNP1 and Taql for SNP4, and is shown for 16 reference genotypes. M $=1 \mathrm{~kb}$ marker. 
Table 3 SNP and haplotype pattern of cinnamate 4-hydroxylase $(\mathrm{C} 4 \mathrm{H})$ encoding gene, investigated with pyrosequencing (SNPs 1 to 4) depicted in $5^{\prime}$ to $3^{\prime}$ direction

\begin{tabular}{|c|c|c|c|c|c|c|c|c|c|}
\hline \multirow[t]{2}{*}{ Haplotypes } & \multicolumn{4}{|c|}{ SNPs from 5 ' to $3^{\prime}$} & \multicolumn{4}{|c|}{$\begin{array}{l}\text { Haplotype frequency (No. of cultivars) } \\
\text { according row number and growth habit }\end{array}$} & \multirow[t]{2}{*}{$\begin{array}{l}\text { Haplotype frequency } \\
\text { (No. of cultivars) }\end{array}$} \\
\hline & SNP1 & SNP2 & SNP3 & SNP4 & $2 r-S$ & $6 r-S$ & $2 r-W$ & $6 r-W$ & \\
\hline$\overline{\mathrm{C}} 4 \mathrm{H} \_\mathrm{H} 1$ & $T$ & C & A & $A$ & 86 & 1 & 38 & 1 & 126 \\
\hline $\mathrm{C} 4 \mathrm{H} \_\mathrm{H} 2$ & C & $\mathrm{T}$ & T & G & 2 & - & 23 & 33 & 58 \\
\hline Unknown & \multicolumn{4}{|c|}{ Missing SNP information } & 6 & 1 & - & 1 & 8 \\
\hline Total & & & & & 94 & 2 & 61 & 35 & 192 \\
\hline
\end{tabular}

All four markers are localized in the 3'-non-coding region of the gene and were observed within a set of 190 European barley cultivars and the mapping parents Steptoe $x$ Morex. $S=$ Spring, $W=$ Winter, $2 r=$ two-rowed, $6 r=$ six-rowed.

fragment showed 100\% identity to the cDNA Y09233 [28]. The consensus sequence of CHS_GM293 derived from 16 reference genotypes showed $88 \%$ identity to Y09233 only. In this $474 \mathrm{bp}$ fragment, 17 SNPs were detected and two of them were converted into pyrosequencing markers. Three of them caused amino acid substitutions (Additional file 5). SNP2 causes an exchange of lysine and arginine, while the adjacent SNP13 and SNP14 were coding for either leucine (CTC) or proline (CCT). Alleles of SNP16 and SNP17 are resulting in either asparagine (AAT) or aspartate (GAC). The fragment CHS_287 is located at the end of the gene and consists of $200 \mathrm{bp}$ exon and $120 \mathrm{bp}$ 3'UTR. After resequencing, 99\% identity with cDNA U43494 [29] was revealed. Two of the 11 detected SNPs generate amino acid exchanges: SNP1 codes for arginine or cysteine and SNP2 for valine or alanine (Additional file 6). It is remarkable that all eight SNPs from GM287_SNP4 to GM287_SNP11 are very close to each other. The SNP1 was converted into a pyrosequencing marker and genotyping of 190 barley accessions was performed with this pyrosequencing marker CHS_GM287_SNP1 (Table 4).

\section{Flavone 3-hydroxylase (F3H)}

Two nearby fragments of the $F 3 H$ with altogether 1339 bp were sequenced and analyzed. The first fragment F3H_1 is localized near the 5 '-end of the gene and contains $167 \mathrm{bp}$

\begin{tabular}{|c|c|c|c|c|c|}
\hline \multirow{2}{*}{$\begin{array}{l}\text { SNP1 } \\
\text { Exon }\end{array}$} & \multicolumn{4}{|c|}{$\begin{array}{c}\text { Genotype frequency } \\
\text { (No. of cultivars) according } \\
\text { row number and growth habit }\end{array}$} & \multirow[t]{2}{*}{$\begin{array}{l}\text { Haplotype frequency } \\
\text { (No. of cultivars) }\end{array}$} \\
\hline & $2 r-S$ & $6 r-5$ & $2 r-W$ & $6 r-W$ & \\
\hline C (Arg) & 94 & 1 & 53 & 24 & 172 \\
\hline T (Cys) & - & 1 & 8 & 9 & 18 \\
\hline $\begin{array}{l}\text { Missing SNP } \\
\text { information }\end{array}$ & - & - & - & 2 & 2 \\
\hline Total & 94 & 2 & 61 & 35 & 192 \\
\hline
\end{tabular}

Coding amino acids are given in brackets. $S=$ Spring, $W=$ Winter, $2 r=$ two-rowed, $6 r=$ six-rowed. of one exon and $597 \mathrm{bp}$ of an intron. Here, 48 SNPs and four InDels were detected in the intron (Figure 4). Four of these SNPs (SNP36, 37, 38 and 39), as well as ID4, were converted into pyrosequencing markers while the large InDel ID3 of 296 bp length was detected by gel electrophoresis.

The second fragment F3H_GM022 with 544 bp length is localized at the 3'-end of the gene containing a $109 \mathrm{bp}$ large intron flanked by a 37 bp exon sequence in $5^{\prime}$ direction and a 336 bp long exon sequence in 3' direction comprising the stop-codon TAG. The 3 'UTR region was partially sequenced as well (Figure 4). Three SNPs and two InDels were detected here. The first two SNPs are located in the intron while SNP3 is located in the 336 bp exon representing a silent mutation. Two InDels of three bp (ID1) and one bp (ID2) length were found in the 3'UTR. All polymorphisms of F3H_GM022 were converted into pyrosequencing markers.

All exon sequences of F3H_1 and GM022 showed high identity to the cDNA X58138 encoding the F3H amino acid sequence of barley [9]. The entire sequence of F3H_1 including the large intron showed no similarity to any published genetic sequences of $\mathrm{F} 3 \mathrm{H}$ whereas the complete sequence of F3H_GM022 including the intron showed high similarity to $\mathrm{F3H}$ gene sequences e.g. AB223024 and AB223026 (http://www.ncbi.nlm.nih.gov) from Triticum aestivum ( $\geq 91 \%)$.

Genotyping was performed with 190 cultivars by applying high-througput marker assays for seven SNPs and two InDels. Both InDels of F3H_GM022 ID1 and ID2 were not included into the haplotype and association analysis due to unclear and rare allele pattern. At least, four haplotypes could be determined. The haplotype F3H_H1 is predominantly found in winter cultivars and the other three haplotypes F3H_H2, F3H_H3 and F3H_H4 are mainly abundant in the spring types (Table 5 ).

\section{Dihydoflavonol reductase (DFR)}

The DFR gene was partially resequenced. The obtained fragment of 949 bp consists of 174 bp from the third exon, followed by a $105 \mathrm{bp}$ large intron and $585 \mathrm{bp}$ of the fourth and last exon with two stop codons, followed by the 3 'UTR 


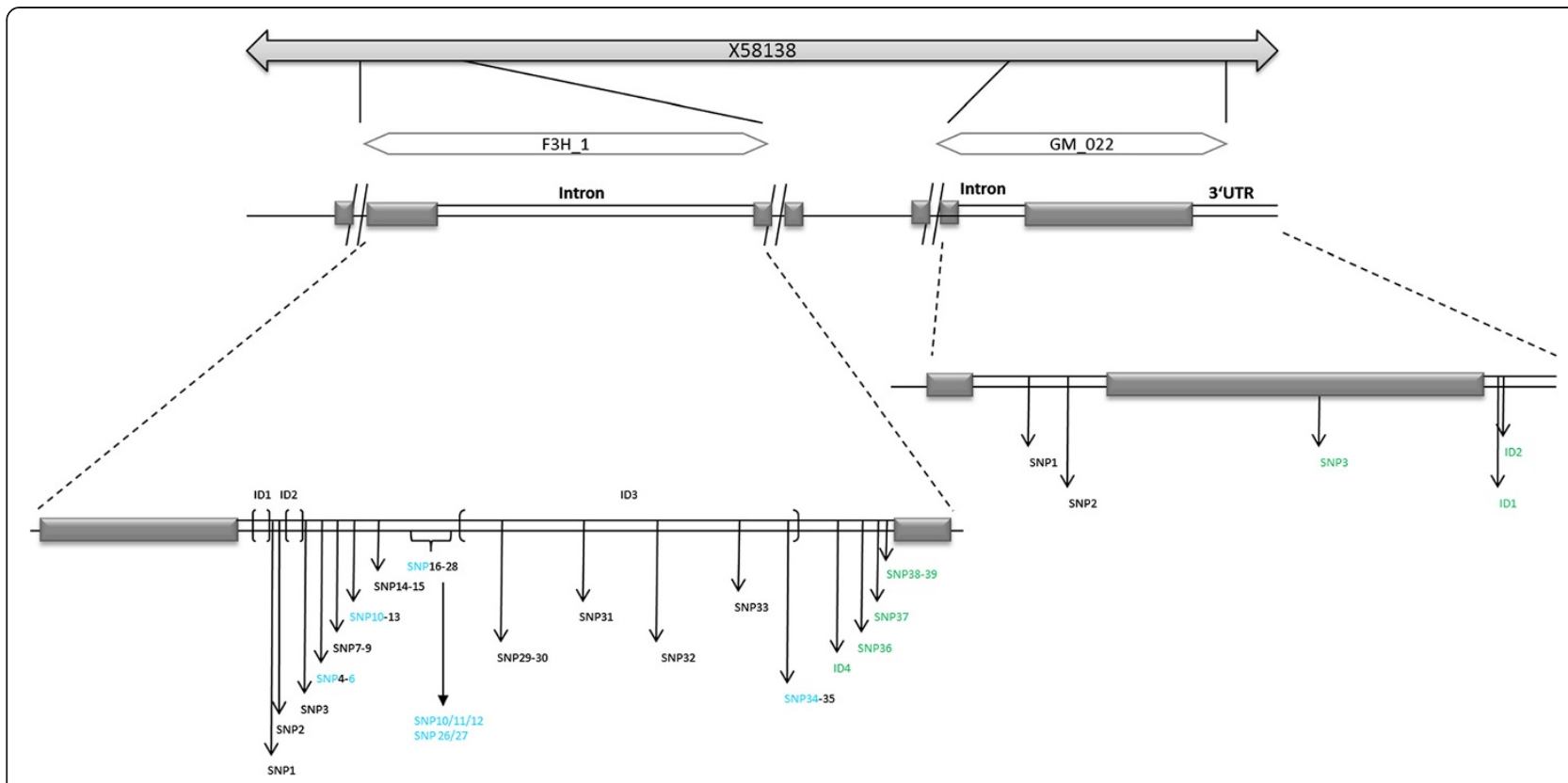

Figure 4 Genetic structure of the flavanone 3-hydroxylase $(\mathbf{F} 3 \mathrm{H})$ gene fragments $\mathrm{F} 3 \mathrm{H} \_\mathbf{1}$ and GM022. Light grey boxes represent exons and white boxes represent introns. The thin line indicates the non-sequenced region. ID - Insertion/Deletion, blue - CAPS marker, green - high-throughput SNP marker.

of $85 \mathrm{bp}$. The sizes of the intron and this exon are in accordance to the results from Kristiansen and Rohde [30]. Resequencing of this candidate gene was performed with three overlapping amplified fragments that were completely identical in their sequence. Altogether, four SNPs and one InDel were found (Additional file 7). The first two SNPs in the third exon display silent mutations. DFR_SNP2 to DFR_SNP4 and DFR_ID1 were converted into pyrosequencing markers. Only SNP4 and ID1 were used for the large scale genotyping due to a rare allele pattern of SNP_2. Four haplotypes resulting from these two polymorphisms were revealed (Table 6). Two haplotypes (DFR_H1 and DFR_H2) are predominantly represented by two-rowed varieties, whereas most of DFR_H3 is represented by six rowed varieties (Table 6). The haplotype DFR_H4 shows a rare allele pattern.

The InDel DFR_ID1 was transformed into a CAPS marker as well. A deletion of two adenine molecules at ID1 generates a recognition site for the restriction enzyme MseI. Thus, all varieties with this deletion were cutted into fragments of 250 and $312 \mathrm{bp}$. This was also confirmed by the pyrosequencing assay for DFR_ID1 (Figure 5).

\section{Genetic mapping}

Genetic mapping of $P A L, C 4 H, C H S$ and $F 3 H$ was performed using pyrosequencing markers found to be polymorphic between the mapping parents Steptoe $\mathrm{x}$ Morex on a set of 77 doubled haploid lines.

For the DFR gene no polymorphism between Steptoe and Morex was found. Therefore, mapping was performed with the segregating population of Morex x Barke by Nils Stein (Leibniz Institute of Plant Genetics and Crop Plant Research, Gatersleben, Germany), calculated with a publicly available set of DArT and SNP markers [31,32]. This gene was mapped with the pyrosequencing marker DFR_SNP4, which is localized in the 3'UTR of the gene. It was localized between the DArT-marker bPb-0094 and the SNP-marker 1_0349 on the long arm of chromosome $3 \mathrm{H}$, which are close to the centromeric region (Figure 6). Two markers for PAL_2, SNP21 detected by a CAPS-assay, and SNP3 by pyrosequencing, were mapped next to each other on chromosome $2 \mathrm{H}$ (Figure 6). Also for C4H_SNP1, mapping was performed using two methods (pyrosequencing and CAPS). Both could be placed at the same position on the long arm of $3 \mathrm{H}$ next to the RFLP marker ABG453 $(1.3 \mathrm{cM})$ (Figure 6). SNPs of the three CHS fragments showed polymorphisms between the mapping parents Steptoe and Morex and were localized on different positions in the barley genome, respectively (Figure 6). This leads to the assumption that the three fragments belong to different gene copies. In previous studies from Christensen et al. [28] at least seven copies of CHS in the barley genome were identified but clear positioning of all these paralogs is still unclear. CHS_GM287_SNP1 was placed on the short arm of chromosome $6 \mathrm{H}$ linked to the marker GBS068. CHS_GM290_SNP1 was localized on the long arm of chromosome $1 \mathrm{H}$, next to the marker Cab2, and CHS_GM293_SNP13 was mapped to the short arm of chromosome $1 \mathrm{H}$, adjacent to the marker MWG837 $(1.6 \mathrm{cM})$. The InDels of both fragments from $\mathrm{F} 3 \mathrm{H}$ were 
Table 5 SNP and haplotype pattern in the adjacent fragments $\mathrm{F3H}$ _ 1 and GM022 of the flavanone 3-hydroxylase (F3H) encoding gene revealed by gel electrophoresis (296 bp InDel) and by pyrosequencing assays in a set of 190 European barley cultivars and the mapping parents Steptoe and Morex

\begin{tabular}{lcc}
\hline Haplotypes & SNPs/IDs from 5' to 3' & $\begin{array}{c}\text { Haplotype frequency } \\
\text { (No. of cultivars) }\end{array}$ \\
according row number & (No. of cultivars) \\
and growth habit &
\end{tabular}

and growth habit

\begin{tabular}{|c|c|c|c|c|c|c|c|c|c|c|c|c|c|c|}
\hline & $\begin{array}{l}\text { F3H1_ID3 } \\
\text { Intron }\end{array}$ & $\begin{array}{c}\text { F3H1_ID4 } \\
\text { Intron }\end{array}$ & $\begin{array}{c}\text { F3H1_SNP36 } \\
\text { Intron }\end{array}$ & $\begin{array}{c}\text { F3H1_SNP37 } \\
\text { Intron }\end{array}$ & $\begin{array}{c}\text { F3H1_SNP38 } \\
\text { Intron }\end{array}$ & $\begin{array}{c}\text { F3H1_SNP39 } \\
\text { Intron }\end{array}$ & $\begin{array}{c}\text { GM022_SNP1 } \\
\text { Intron }\end{array}$ & $\begin{array}{c}\text { GM022_SNP2 } \\
\text { Intron }\end{array}$ & $\begin{array}{c}\text { GM022_SNP3 } \\
\text { Exon }\end{array}$ & $2 r-S$ & $6 r-S$ & $2 r-W$ & $6 r-W$ & \\
\hline$\overline{\mathrm{F} 3 \mathrm{H} \_\mathrm{H} 1}$ & $\begin{array}{c}296 \mathrm{bp} \\
\text { insert }\end{array}$ & - & C & C & $C$ & $G$ & C & C & C (Leu) & 15 & 1 & 59 & 31 & 106 \\
\hline $\mathrm{F} 3 \mathrm{H} \_\mathrm{H} 2$ & - & AT & T & C & G & A & G & A & C (Leu) & 29 & 1 & 1 & 1 & 32 \\
\hline $\mathrm{F} 3 \mathrm{H} \_\mathrm{H} 3$ & $\begin{array}{c}296 \mathrm{bp} \\
\text { insert }\end{array}$ & - & C & C & G & G & G & A & $\mathrm{T}(\mathrm{Leu})$ & 28 & - & 1 & 1 & 30 \\
\hline $\mathrm{F} 3 \mathrm{H} \_\mathrm{H} 4$ & - & AT & C & A & G & A & G & A & C (Leu) & 13 & - & - & - & 13 \\
\hline Unknown & \multirow{2}{*}{\multicolumn{9}{|c|}{ Missing SNP information }} & 9 & & - & 2 & 8 \\
\hline Total & & & & & & & & & & 94 & 2 & 61 & 35 & 192 \\
\hline
\end{tabular}

Coding amino acids are given in brackets. $I D=$ Insertion/Deletion, $S=$ Spring, $W=$ Winter, $2 r=$ two-rowed, $6 r=$ six-rowed. 
Table 6 Haplotype pattern resulting from one InDel (ID1) and the SNP4 (in 5' to 3' direction) of the dihydoflavonol reductase (DFR) encoding gene investigated by pyrosequencing assays in a set of 190 European barley cultivars and the mapping parents Steptoe and Morex

\begin{tabular}{|c|c|c|c|c|c|c|c|}
\hline \multirow[t]{3}{*}{ Haplotypes } & \multicolumn{2}{|c|}{ SNPs from $5^{\prime}$ to $3^{\prime}$} & \multicolumn{4}{|c|}{$\begin{array}{l}\text { Haplotype frequency (No. of cultivars) } \\
\text { according row number and growth habit }\end{array}$} & \multirow[t]{3}{*}{$\begin{array}{l}\text { Haplotype frequency } \\
\text { (No. of cultivars) }\end{array}$} \\
\hline & ID1 & SNP4 & $2 r-S$ & $6 r-S$ & $2 r-W$ & $6 r-W$ & \\
\hline & Intron & 3'UTR & & & & & \\
\hline$\overline{\mathrm{DFR} \_\mathrm{H} 1}$ & AA & C & 61 & - & 36 & 4 & 101 \\
\hline $\mathrm{DFR} \_\mathrm{H} 2$ & - & C & 21 & - & 16 & - & 37 \\
\hline DFR_H3 & AA & $\mathrm{T}$ & 7 & - & 6 & 24 & 37 \\
\hline DFR_H4 & - & $\mathrm{T}$ & 3 & 2 & 2 & 7 & 14 \\
\hline unknown & \multicolumn{2}{|c|}{ missing SNP information } & 2 & - & 1 & - & 3 \\
\hline Total & & & 94 & 2 & 61 & 35 & 192 \\
\hline
\end{tabular}

$\mathrm{ID}=$ Insertion/Deletion, $S=$ Spring, $W=$ Winter, $2 r=$ two-rowed, $6 r=$ six-rowed.

mapped using the pyrosequencing markers F3H_1_ID4 and GM022_ID2. These were localized on the long arm of chromosome $2 \mathrm{H}$, linked with the RFLP marker ABC252 (Figure 6), which is in accordance with the findings of Khlestkina et al. [33].

Here in this study, the genetic markers for $P A L, C 4 H$, $C H S$ and $D F R$ were mapped in the barley genome for the first time. Previous findings that $C H S$ and $P A L$ are represented by gene families were supported by mapping of non-overlapping markers to different positions in the barley genome (Figure 6). Location of F3H supports the results from Khlestkina et al. [33]. Recent advances in obtaining a physical map by a next generation sequence approach in barley [34] permitted the assignment of the investigated genes on barley contigs (Table 7). In all cases, the results obtained by genetic mapping were confirmed by the best BLAST-hit, including two locations for different CHS fragments on chromosomes $1 \mathrm{H}$ and $6 \mathrm{HL}$. This confirmed previous mapping results, where CHS was placed on chromosome 5 (old nomenclature) equaling chromosome $1 \mathrm{H}$ (new nomenclature) [35]. Additional secondary BLAST hits indicated the presence of further gene copies for all tested genes (Table 7).
Association to kernel and malting quality parameters

Barley grain quality parameters are inevitable to evaluate the utility of grains to ensure constant conditions during the malting process. Associations of genetic variation to phenotypic characteristics help to identify molecular markers responsible for good malting quality. They can serve as a selection tool for accelerating breeding processes. The phenotypic variation of different malting and kernel quality parameters were related to structural genetic differences (SNPs, InDels).

For certain candidate genes, the haplotype distribution within the set of 190 European barley cultivars follows their assignment to spring or winter type, or row number. For example, haplotypes DFR_1 and DFR_2 as well as PAL_H1 are mostly represented in two-rowed varieties (Table 2 and 6). Similar results were obtained for $\mathrm{C} 4 \mathrm{H}$ (Table 3), where haplotype $\mathrm{C} 4 \mathrm{H} \_1$ also represents mainly two-rowed varieties. The haplotypes $\mathrm{H} 1, \mathrm{H} 2$ and $\mathrm{H} 3$ of $\mathrm{F} 3 \mathrm{H}$ are mostly found in the spring-pool whereas the winter varieties mainly were assigned to the most abundant haplotype F3H_H1 (Table 5). As a high population structure effect was revealed for these barley populations a correction for population structure within this set of

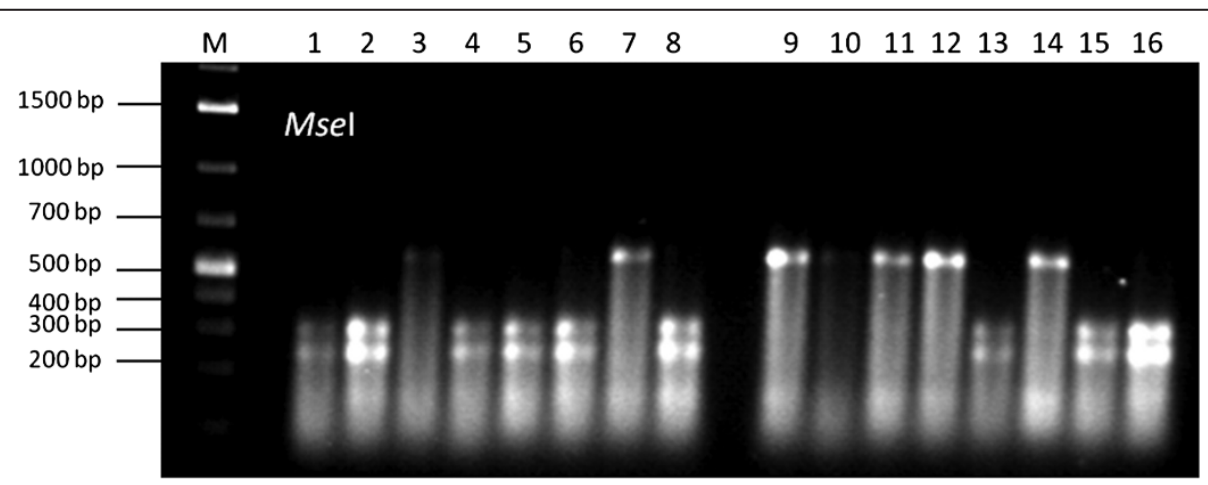

Figure 5 Restriction pattern observed by the CAPS marker DFR_ ID1 developed for the two bp InDel in the dihydoflavonol reductase (DFR) encoding gene, shown for 16 reference genotypes. $M=1 \mathrm{~kb}$ marker. 


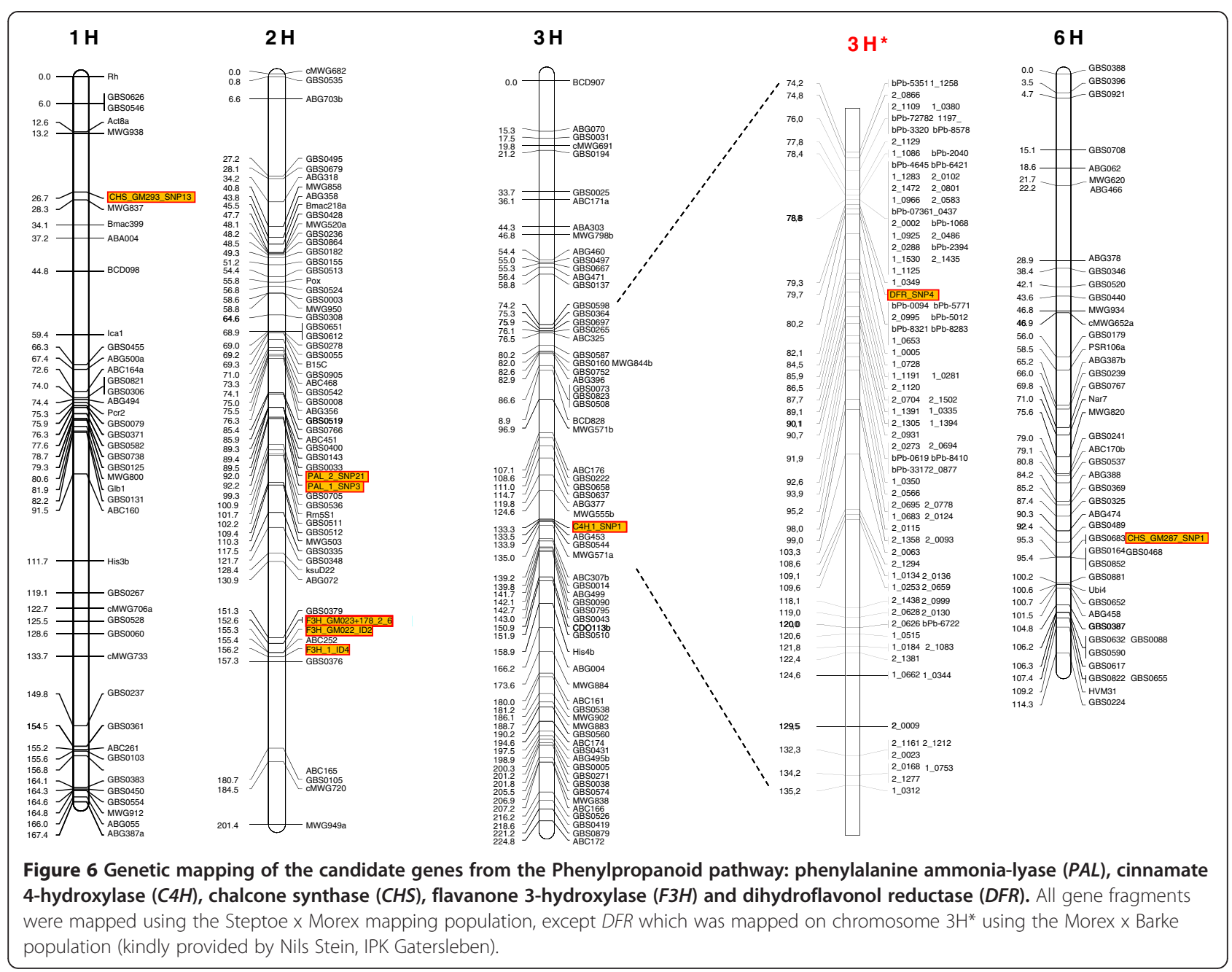

barley accessions is necessary when performing an association study in order to reduce the amount of false positives and negatives [36]).

Three different models were taken into account in order to reveal significant marker-trait associations: principle component analysis (PCA) by using a combination of population structure and kinship, general linear model (GLM) by using population structure and mixed linear model (MLM) by using kinship. Information about population structure was based on a Q5-matrix with random 22 SSR markers. As it was shown in a previous study, multi-allelic SSR markers serve as a more accurate tool to reveal the population structure [36].

Association results significant for all three models are given for four genes, namely $P A L, C 4 H, F 3 H, D F R$ (Tables 8 and 9). The complete data are represented in the Additional file 8 .

Three haplotypes represented by four SNPs of the $P A L$ gene were taken into account to reveal their impact on kernel and malting quality parameters. The haplotypes PAL_H2 and PAL_H3 are significant for kernel formation
(Table 8). Both haplotypes share the same allele for SNP_1 but differ in SNP3, SNP4 and SNP5, which are individually significant for this trait. SNP1 was found to be significant for kernel yield. This trait is also influenced by haplotypes $\mathrm{H} 1$ and $\mathrm{H} 2$ that differ in SNP1. The SNPs 3, 4 and 5 were highly significant for glassiness and kernel formation in all three models (Table 9). A high portion of glassy kernels in a malting barley charge leads to an unsatisfactory brewing result. They cause higher turbidity and opal wort, which is not desired. Another important malting parameter is the 'Brabender', which serves as an indicator for cytolytic degradation processes in the barley grain. Here, a high value is desirable. Kernel yield (KY) was significantly correlated with SNP1. The allele A coding for adenine in the PAL gene is responsible for the significant association of the haplotype PAL_H1 with higher yield (Additional file 8).

All polymorphic sites found for $\mathrm{C} 4 \mathrm{H}$ were associated with kernel yield and viscosity. The malting parameter viscosity describes the degradation of hemicelluloses catalyzed by endo- $\beta$-glucanases. This factor influences the foam stability of the beer and lautering time. 
Table 7 Physical mapping of candidate genes

\begin{tabular}{|c|c|c|c|c|}
\hline $\begin{array}{l}\text { Gene } \\
\text { fragment }\end{array}$ & Best blastN hits & Chromosome & Score & E value \\
\hline \multirow[t]{11}{*}{ PAL_1 } & morex_contig_46437 & $2 \mathrm{HL}$ & 1061 & 0.0 \\
\hline & morex_contig_40780 & $2 \mathrm{HL}$ & 841 & 0.0 \\
\hline & morex_contig_8668 & $2 \mathrm{HL}$ & 810 & 0.0 \\
\hline & morex_contig_103333 & $2 \mathrm{HS}$ & 673 & 0.0 \\
\hline & morex_contig_52512 & $6 \mathrm{HL}$ & 664 & 0.0 \\
\hline & morex_contig_135397 & $6 \mathrm{HL}$ & 598 & $8 e-169$ \\
\hline & morex_contig_49473 & $6 \mathrm{HL}$ & 554 & $9 e-156$ \\
\hline & morex_contig_1944918 & $2 \mathrm{HS}$ & 533 & $3 e-149$ \\
\hline & morex_contig_244188 & $1 \mathrm{H}$ & 452 & $8 e-125$ \\
\hline & morex_contig_138406 & $3 \mathrm{HS}$ & 370 & $2 \mathrm{e}-100$ \\
\hline & morex_contig_2558942 & $1 \mathrm{H}$ & 172 & $1 e-40$ \\
\hline \multirow[t]{13}{*}{ PAL_2 } & morex_contig_46437 & $2 \mathrm{HL}$ & 1050 & 0.0 \\
\hline & morex_contig_8668 & $2 \mathrm{HL}$ & 848 & 0.0 \\
\hline & morex_contig_103333 & $2 \mathrm{HS}$ & 722 & 0.0 \\
\hline & morex_contig_52512 & $6 \mathrm{HL}$ & 717 & 0.0 \\
\hline & morex_contig_135397 & $6 \mathrm{HL}$ & 645 & 0.0 \\
\hline & morex_contig_49473 & $6 \mathrm{HL}$ & 587 & $2 \mathrm{e}-165$ \\
\hline & morex_contig_2558942 & $1 \mathrm{H}$ & 513 & $3 e-143$ \\
\hline & morex_contig_138406 & $3 \mathrm{HS}$ & 497 & $2 \mathrm{e}-138$ \\
\hline & morex_contig_281235 & $2 \mathrm{HL}$ & 468 & $1 e-129$ \\
\hline & morex_contig_40780 & $2 \mathrm{HL}$ & 410 & $2 \mathrm{e}-112$ \\
\hline & morex_contig_1586542 & $2 \mathrm{HS}$ & 370 & $2 \mathrm{e}-100$ \\
\hline & morex_contig_1944918 & $2 \mathrm{HS}$ & 288 & $2 \mathrm{e}-75$ \\
\hline & morex_contig_244188 & $1 \mathrm{H}$ & 170 & $4 e-40$ \\
\hline $\mathrm{C} 4 \mathrm{H}_{-} 1$ & morex_contig_135422 & $3 \mathrm{HL}$ & 877 & 0.0 \\
\hline \multirow[t]{4}{*}{$\mathrm{C} 4 \mathrm{H} \_4$} & morex_contig_135422 & $3 \mathrm{HL}$ & 1178 & 0.0 \\
\hline & morex_contig_57093 & $7 \mathrm{HL}$ & 416 & $6 e-114$ \\
\hline & morex_contig_54181 & $3 \mathrm{HS}$ & 361 & $1 e-97$ \\
\hline & morex_contig_1569145 & $1 \mathrm{H}$ & 333 & $6 e-89$ \\
\hline \multirow[t]{6}{*}{$\mathrm{CHS}_{-} 1$} & morex_contig_127876 & $1 \mathrm{H}$ & 455 & $3 e-126$ \\
\hline & morex_contig_45546 & $1 \mathrm{H}$ & 300 & $1 e-79$ \\
\hline & morex_contig_140601 & $2 \mathrm{HS}$ & 181 & $8 e-44$ \\
\hline & morex_contig_65180 & $2 \mathrm{HL}$ & 172 & $4 e-41$ \\
\hline & morex_contig_48619 & $2 \mathrm{HS}$ & 165 & $6 e-39$ \\
\hline & morex_contig_359532 & $1 \mathrm{H}$ & 154 & $1 e-35$ \\
\hline \multirow[t]{6}{*}{ CHS_2 } & morex_contig_127876 & $1 \mathrm{H}$ & 457 & $7 e-127$ \\
\hline & morex_contig_45546 & $1 \mathrm{H}$ & 277 & $1 e-72$ \\
\hline & morex_contig_359532 & $1 \mathrm{H}$ & 242 & $3 e-62$ \\
\hline & morex_contig_65180 & $2 \mathrm{HL}$ & 141 & $7 e-32$ \\
\hline & morex_contig_48619 & $2 \mathrm{HS}$ & 141 & $7 e-32$ \\
\hline & morex_contig_140601 & $2 \mathrm{HS}$ & 136 & $3 e-30$ \\
\hline \multirow[t]{2}{*}{ CHS_GM290 } & morex_contig_127876 & $1 \mathrm{H}$ & 1150 & 0.0 \\
\hline & morex_contig_45546 & $1 \mathrm{H}$ & 798 & 0.0 \\
\hline
\end{tabular}

Table 7 Physical mapping of candidate genes (Continued)

\begin{tabular}{|c|c|c|c|c|}
\hline & morex_contig_65180 & $2 \mathrm{HL}$ & 605 & $6 e-171$ \\
\hline & morex_contig_140601 & $2 \mathrm{HS}$ & 578 & $8 e-163$ \\
\hline & morex_contig_48619 & $2 \mathrm{HS}$ & 533 & $3 e-149$ \\
\hline & morex_contig_38618 & $1 \mathrm{H}$ & 178 & $3 e-42$ \\
\hline & morex_contig_359532 & $1 \mathrm{H}$ & 138 & $2 e-30$ \\
\hline & morex_contig_37159 & $6 \mathrm{HL}$ & 120 & $7 e-25$ \\
\hline \multirow[t]{9}{*}{ CHS_GM293 } & morex_contig_45546 & $1 \mathrm{H}$ & 839 & 0.0 \\
\hline & morex_contig_127876 & $1 \mathrm{H}$ & 605 & $4 e-171$ \\
\hline & morex_contig_65180 & $2 \mathrm{HL}$ & 488 & $9 e-136$ \\
\hline & morex_contig_140601 & $2 \mathrm{HS}$ & 452 & $6 e-125$ \\
\hline & morex_contig_48619 & $2 \mathrm{HS}$ & 412 & $5 e-113$ \\
\hline & morex_contig_359532 & $1 \mathrm{H}$ & 217 & $2 e-54$ \\
\hline & morex_contig_96161 & - & 156 & $7 e-36$ \\
\hline & morex_contig_37159 & $6 \mathrm{HL}$ & 150 & $3 e-34$ \\
\hline & morex_contig_38618 & $1 \mathrm{H}$ & 143 & $4 e-32$ \\
\hline \multirow[t]{3}{*}{ CHS_GM287 } & bowman_contig_128263 & $6 \mathrm{HL}$ & 571 & $6 e-161$ \\
\hline & morex_contig_96161 & - & 571 & $6 e-161$ \\
\hline & morex_contig_42645 & $4 \mathrm{HS}$ & 188 & $7 e-46$ \\
\hline \multirow[t]{6}{*}{ F3H_1 } & morex_contig_48553 & $2 \mathrm{HL}$ & 495 & $1 e-137$ \\
\hline & morex_contig_52807 & $1 \mathrm{H}$ & 421 & $2 \mathrm{e}-115$ \\
\hline & morex_contig_48831 & $2 \mathrm{HL}$ & 408 & $1 e-111$ \\
\hline & morex_contig_367028 & $4 \mathrm{HL}$ & 365 & $1 e-98$ \\
\hline & morex_contig_47538 & $7 \mathrm{HS}$ & 361 & $1 e-97$ \\
\hline & morex_contig_1562556 & $7 \mathrm{HL}$ & 318 & $2 e-84$ \\
\hline F3H_GM022 & morex_contig_48553 & $2 \mathrm{HL}$ & 931 & 0.0 \\
\hline \multirow[t]{3}{*}{ DFR_1 } & morex_contig_50663 & $3 \mathrm{HL}$ & 874 & 0.0 \\
\hline & morex_contig_90563 & $6 \mathrm{HL}$ & 352 & $5 e-95$ \\
\hline & morex_contig_77596 & $6 \mathrm{HL}$ & 320 & $3 e-85$ \\
\hline \multirow[t]{3}{*}{ DFR_4 } & morex_contig_50663 & $3 \mathrm{HL}$ & 1442 & 0.0 \\
\hline & morex_contig_90563 & $6 \mathrm{HL}$ & 875 & 0.0 \\
\hline & morex_contig_77596 & $6 \mathrm{HL}$ & 830 & 0.0 \\
\hline
\end{tabular}

Final attenuation and fermentable extract were significantly associated with the haplotype 4 of $F 3 H$, which occurs only in two-rowed spring barleys (Table 5 ). The final attenuation describes the enzymatic activity of amylases and is correlated to dilution properties of the malt extract. A close correlation exists with the malting parameter fermentable extract [37]. Combining SNPs to haplotype patterns can provide more information than single SNPs. This is illustrated by the significant association results of F3H_H4 with these traits, which was not found considering their single SNPs. The haplotypes 1 and 3 of $F 3 H$ showed associations to kernel raw protein (KRP), kernel yield (KY) and $\mathrm{pH}$ (Table 8). The haplotype 3 (F3H_H3) is associated to a lower raw kernel protein content (K_RP) and is mainly 
Table 8 Significant marker trait associations of haplotypes found in 190 European barley cultivars and selected kernel and malting quality parameters for phenylalanine ammonia-lyase (PAL), cinnamate 4-hydroxylase (C4H), flavanone 3-hydroxylase $(F 3 H)$ and dihydroflavonol reductase (DFR)

\begin{tabular}{|c|c|c|c|c|c|c|c|c|c|c|c|}
\hline \multirow[t]{2}{*}{ Haplotype } & \multirow[t]{2}{*}{ Trait } & \multirow[t]{2}{*}{ Unit } & \multicolumn{3}{|c|}{ MLM_PCA } & \multicolumn{3}{|c|}{ MLM_QK } & \multicolumn{3}{|c|}{ GLM_Q } \\
\hline & & & $\bar{P}$ & $\mathrm{R}^{2}$ Model & $\mathrm{R}^{2}$ Marker & $\bar{P}$ & $\mathrm{R}^{2}$ Model & $\mathrm{R}^{2}$ Marker & $\bar{P}$ & $\mathrm{R}^{2}$ Model & $\mathrm{R}^{2}$ Marker \\
\hline$\overline{\mathrm{PAL}} \mathrm{H} 1$ & KY & $\mathrm{dt} / \mathrm{ha}$ & $0.04^{*}$ & 0.643 & 0.018 & $0.007^{* *}$ & 0.709 & 0.022 & $0.002^{* * 1}$ & 0.597 & 0.039 \\
\hline \multirow[t]{2}{*}{ PAL_H2 } & $\mathrm{KF}$ & $1-9$ & $0.01^{*}$ & 0.371 & 0.035 & $0.005^{* *}$ & 0.373 & 0.040 & $0.004^{* *}$ & 0.370 & 0.043 \\
\hline & KY & $\mathrm{dt} / \mathrm{ha}$ & $0.039 *$ & 0.643 & 0.018 & $0.046^{*}$ & 0.699 & 0.012 & $0.018^{*}$ & 0.582 & 0.024 \\
\hline PAL_H3 & $\mathrm{KF}$ & $1-9$ & $0.006^{* *}$ & 0.378 & 0.042 & $0.016^{*}$ & 0.363 & 0.030 & $0.009^{* *}$ & 0.361 & 0.034 \\
\hline $\mathrm{C} 4 \mathrm{H} \_\mathrm{H} 1$ & KY & $\mathrm{dt} / \mathrm{ha}$ & $0.007^{* *}$ & 0.655 & 0.030 & $0.004^{* * 2}$ & 0.711 & 0.025 & $0.001^{* * * 2}$ & 0.601 & 0.043 \\
\hline \multirow[t]{2}{*}{$\mathrm{F} 3 \mathrm{H} \_\mathrm{H} 1$} & $\mathrm{KRP}$ & $\%$ & $0.001^{* * * 3}$ & 0.605 & 0.031 & $0.002^{* * 3}$ & 0.568 & 0.025 & $0.002^{* * 3}$ & 0.568 & 0.025 \\
\hline & KY & $\mathrm{dt} / \mathrm{ha}$ & $0.003^{* *}$ & 0.662 & 0.036 & $0.014^{*}$ & 0.584 & 0.026 & $0.014^{*}$ & 0.584 & 0.026 \\
\hline \multirow[t]{2}{*}{$\mathrm{F} 3 \mathrm{H} \_\mathrm{H} 3$} & $\mathrm{KRP}$ & $\%$ & $0.006^{* *}$ & 0.595 & 0.021 & $0.001^{* * 3}$ & 0.572 & 0.028 & $0.001^{* * * 3}$ & 0.572 & 0.028 \\
\hline & $\mathrm{pH}$ & $\mathrm{pH}$ & $0.035^{*}$ & 0.375 & 0.032 & $0.011^{*}$ & 0.253 & 0.048 & $0.011^{*}$ & 0.253 & 0.048 \\
\hline \multirow[t]{2}{*}{$\mathrm{F} 3 \mathrm{H} \_\mathrm{H} 4$} & FiAt & $\%$ & $0.002^{* * 3}$ & 0.376 & 0.070 & $0.025^{*}$ & 0.090 & 0.043 & $0.025^{*}$ & 0.090 & 0.043 \\
\hline & FEX & $\%$ & $0.007^{* *}$ & 0.522 & 0.073 & $0.046^{*}$ & 0.199 & 0.050 & $0.046^{*}$ & 0.199 & 0.050 \\
\hline \multirow[t]{3}{*}{ DFR_H3 } & SF $2.2-2.5 \mathrm{~mm}$ & $\%$ & $0.033^{*}$ & 0.250 & 0.028 & $0.025^{*}$ & 0.271 & 0.027 & $0.030^{*}$ & 0.187 & 0.028 \\
\hline & Brab & HE & $0.022^{*}$ & 0.557 & 0.037 & $0.002^{* * 3}$ & 0.496 & 0.063 & $0.001^{* * * 3}$ & 0.214 & 0.117 \\
\hline & Visc & mPas & $0.031^{*}$ & 0.679 & 0.017 & $0.004^{* *}$ & 0.681 & 0.027 & $0.004^{* *}$ & 0.494 & 0.043 \\
\hline
\end{tabular}

Different statistical linear models were considered: 1. Mixed linear model $(M L M)$ with principal component analysis $(P C A)$, 2. MLM with kinship $(K)$, 3. General linear model (GLM) with population structure $(Q)$, significant at ${ }^{*} P \leq 0.05$, ${ }^{* * P} \leq 0.01$, ${ }^{* * *} P \leq 0.001$ or after Bonferroni correction with ${ }^{1} P<0.0033,{ }^{2} P<0.005,{ }^{3} P<0.0025$. Trait abbreviations are: $K Y=$ kernel yield [dt/ha], $K F=$ kernel formation [1-9], $S F=$ Sieve fraction, $K \_R P=$ kernel raw protein [\%], $p H=p h$-value, FiAt $=$ final attenuation, FEX $=$ Fermentable extract, Brab $=$ brabender, Visc $=$ viscosity [mPas $]$.

Table 9 Significant marker trait associations between SNPs and selected kernel and malting quality parameters detected in a set of 190 European barley cultivars for following candidate genes of the phenylpropanoid pathway: phenylalanine ammonia-lyase $(P A L)$, cinnamate 4-hydroxylase $(C 4 H)$, flavanone 3-hydroxylase $(F 3 H)$ and dihydroflavonol reductase (DFR)

\begin{tabular}{|c|c|c|c|c|c|c|c|c|c|c|c|}
\hline \multirow[t]{2}{*}{ Marker } & \multirow[t]{2}{*}{ Trait } & \multirow[t]{2}{*}{ Unit } & \multicolumn{3}{|c|}{ MLM_PCA } & \multicolumn{3}{|c|}{ MLM_QK } & \multicolumn{3}{|c|}{ GLM_Q } \\
\hline & & & $\bar{P}$ & $\mathrm{R}^{2}$ Model & $\mathrm{R}^{2}$ Marker & $P$ & $\mathrm{R}^{2}$ Model & $\mathrm{R}^{2}$ Marker & $\bar{P}$ & $\mathrm{R}^{2}$ Model & $\mathrm{R}^{2}$ Marker \\
\hline$\overline{P A L}$ SNP1 & KY & $\mathrm{dt} / \mathrm{ha}$ & $0.041^{*}$ & 0.643 & 0.018 & $0.007^{* *}$ & 0.709 & 0.022 & $0.002^{* * 1}$ & 0.597 & 0.039 \\
\hline \multirow[t]{2}{*}{ PAL_SNP3 } & KF & $1-9$ & $0.006^{* *}$ & 0.373 & 0.043 & $0.015^{*}$ & 0.358 & 0.031 & $0.009 * *$ & 0.356 & 0.036 \\
\hline & Glass & $\%$ & $0.000^{* * * 1}$ & 0.499 & 0.132 & $0.000^{* * * 1}$ & 0.563 & 0.079 & $0.000^{* * * 1}$ & 0.271 & 0.147 \\
\hline \multirow[t]{2}{*}{ PAL_SNP4 + PAL_SNP5 } & $\mathrm{KF}$ & $1-9$ & $0.006^{* *}$ & 0.378 & 0.042 & $0.016^{*}$ & 0.363 & 0.030 & $0.009^{* *}$ & 0.361 & 0.034 \\
\hline & Glass & $\%$ & $0.000^{* * * 1}$ & 0.499 & 0.132 & $0.000^{* * * 1}$ & 0.562 & 0.079 & $0.000^{* * * 1}$ & 0.271 & 0.147 \\
\hline C4H_SNP1 & KY & $\mathrm{dt} / \mathrm{ha}$ & $0.047^{*}$ & 0.677 & 0.016 & $0.010^{* *}$ & 0.746 & 0.018 & $0.003^{* *}$ & 0.645 & 0.034 \\
\hline C4H_SNP2 & Visc & mPas & $0.026^{*}$ & 0.680 & 0.018 & $0.000^{* * * 1}$ & 0.703 & 0.048 & $0.000 * * * 1$ & 0.519 & 0.068 \\
\hline C4H_SNP4 & Visc & mPas & $0.032^{*}$ & 0.670 & 0.018 & $0.000^{* * * 1}$ & 0.694 & 0.050 & $0.000^{* * * 1}$ & 0.503 & 0.071 \\
\hline CHS_GM287_SNP1 & Visc & mPas & $0.001^{* * * 2}$ & 0.702 & 0.041 & $0.000^{* * * 2}$ & 0.726 & 0.071 & $0.000 * * * 2$ & 0.576 & 0.125 \\
\hline \multirow{2}{*}{$\begin{array}{l}\text { F3H1_SNP38 + } \\
\text { F3H_GM022_SNP1 }\end{array}$} & K_RP & $\%$ & $0.002^{* *}$ & 0.601 & 0.027 & $0.014^{*}$ & 0.592 & 0.015 & $0.010^{*}$ & 0.561 & 0.018 \\
\hline & KY & $\mathrm{dt} / \mathrm{ha}$ & $0.038^{*}$ & 0.645 & 0.018 & $0.039 *$ & 0.700 & 0.013 & $0.048^{*}$ & 0.575 & 0.017 \\
\hline \multirow[t]{2}{*}{ F3H_GM022_SNP2 } & K_RP & $\%$ & $0.001^{* * * 3}$ & 0.606 & 0.031 & $0.004^{* *}$ & 0.598 & 0.021 & $0.003^{* *}$ & 0.568 & 0.024 \\
\hline & KY & $\mathrm{dt} / \mathrm{ha}$ & $0.038^{*}$ & 0.645 & 0.018 & $0.022^{*}$ & 0.703 & 0.016 & $0.024^{*}$ & 0.580 & 0.022 \\
\hline F3H_GM022_SNP3 & K_RP & $\%$ & $0.024^{*}$ & 0.586 & 0.015 & $0.004^{* *}$ & 0.594 & 0.021 & $0.003^{* *}$ & 0.564 & 0.024 \\
\hline DFR_SNP4 & Brab & $\mathrm{HE}$ & $0.013^{*}$ & 0.563 & 0.042 & $0.010^{*}$ & 0.481 & 0.044 & $0.005^{* *}$ & 0.183 & 0.086 \\
\hline
\end{tabular}

Three different statistical models were considered: 1. Mixed linear model $(M L M)$ with principal component analysis $(P C A)$. 2. MLM with kinship (K), 3. General linear model (GLM) considering population structure, significant at ${ }^{*} \mathrm{P} \leq 0.05$, ${ }^{* *} \mathrm{P} \leq 0.01$, ${ }^{* * *} \mathrm{P} \leq 0.001$ or after Bonferroni correction with ${ }^{1} \mathrm{P}<0.0025,{ }^{2} \mathrm{P}<0.01,{ }^{3} \mathrm{P}<0.0014$. Trait abbreviations are: $K Y=$ kernel yield [dt/ha], $K F=$ kernel formation [1-9], $K \_R P=$ kernel raw protein [\%], Brab= brabender, Glass $=$ glassiness, Visc $=$ viscosity [mPas] 
found in the 2-rowed spring cultivars (Table 5). Differences in raw kernel protein (K_RP) assigned to different SNP alleles (a) or haplotypes (b) for $F 3 H$ are shown in Figure 7. For a good malting and brewing quality, a low raw protein concentration in kernels is desired.

Only one SNP of the CHS gene could be converted into a pyrosequencing marker. For this marker trait association (MTA), a high variance was observed for viscosity of the malt extract. Low viscosity values were mainly found in accessions having the favorable C-allele of SNP1, which was true for all investigated 2-rowed spring barleys.

In case of $D F R$, haplotype 3 was found to be significantly associated with sieve fraction (SF), brabender and viscosity. This haplotype is predominantly present in winter cultivars.

In some cases, trait-gene combinations were significant with single SNPs as well as with haplotypes, such as kernel yield and kernel formation with PAL, kernel yield with $\mathrm{C} 4 \mathrm{H}$, kernel raw protein with $\mathrm{F} 3 \mathrm{H}$ and Brabender with DFR. Here the evaluation was based on the P-values (Tables 8 and 9), while the $R^{2}$ values explain the percentage of phenotypic variance explained by the model and by the marker. In some cases, the associations of the haplotypes confirm the SNPs, f.e. PAL_SNP1 is specific for PAL_H1 (Table 2) and both were significant for kernel yield (Tables 8 and 9). Another example is the significant association of $\mathrm{F} 3 \mathrm{H} \_\mathrm{H} 1$ with kernel raw protein which is also detected with F3H1_SNP38, a marker specific for F3H_H1 (Table 5).

When Bonferroni correction for multiple testing was applied, the number of significant associations was reduced (Tables 8 and 9). For SNPs, glassiness with PAL and viscosity with CHS remained significant in all three models, while viscosity with $\mathrm{C} 4 \mathrm{H}$ was significant with two models. For the haplotypes, kernel raw protein with F3H remained significant in three models, and kernel yield with $\mathrm{C} 4 \mathrm{H}$ and Brabender with DFR were significant in two models after correction for multiple testing. By empiric means it cannot be decided which statistic model is the "correct model", therefore significant associations observed in several statistical models are a good indication for the reliability of a marker trait association.

The comparison of our association results to other malting quality QTL-studies [38,39] was difficult due to the use of different markers in these maps. A QTL for kernel plumpness, malt extract and diastatic power proximal of marker MWG938 on chromosome $1 \mathrm{H}$ is in the approximate location of our mapped CHS PCR fragment GM293 [40]. However, we did not discover any marker trait association for this fragment, while our newly detected MTAs were not described before.

While the testing of bi-allelic SNPs only permits the forming of two groups during association analysis, the combination of several SNPs to a haplotype results in a multi-allelic genotypic entity. In both cases, the resulting significance levels were often relatively low. A significant association between a trait and a SNP or haplotype of a gene does not proof the causal functional involvement of a gene in trait expression. The association also could be obtained by linkage disequilibrium present in the genome and also other factors, such as effects of environment play a role. In fact, some of the tested traits, such as color of beer are possibly caused by genes of the phenylpropanoid pathway. Other tested traits like kernel development appear to be unrelated to this pathway. Therefore, the newly developed SNP-markers are related to this specific metabolic pathway described here.

\section{Conclusions}

A high gene-dependent variation of SNP-patterns was found for all candidate genes related to the phenylpropanoid pathway. Combination of SNPs to haplotypes revealed in most cases the divergence of habit (winter and spring varieties)
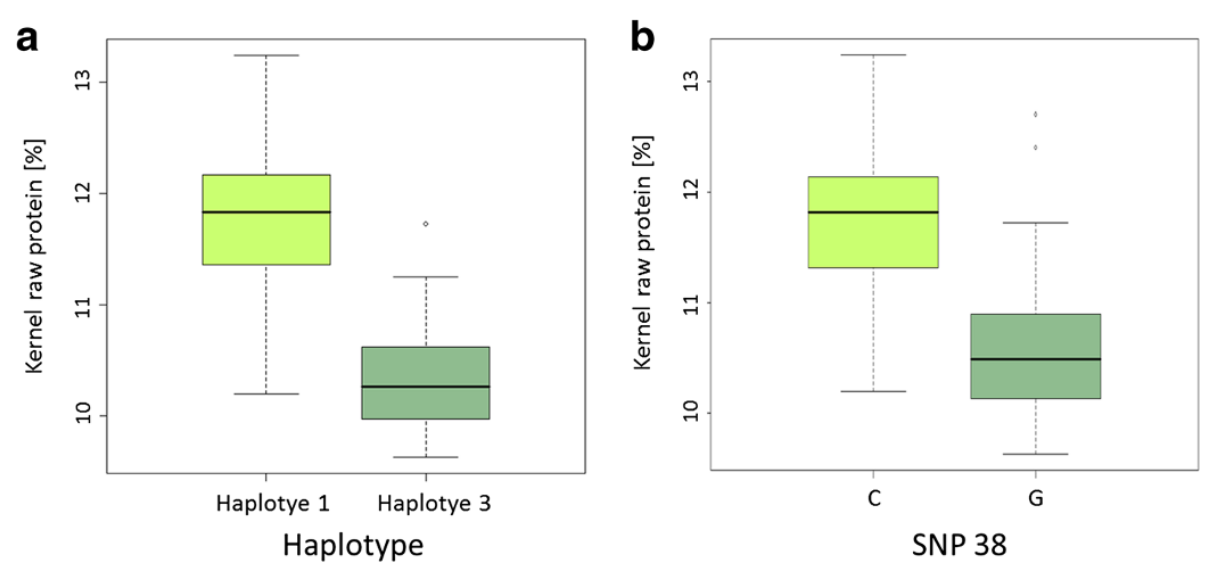

Figure 7 Level of kernel raw protein assigned to a) $F 3 H$ haplotypes 1 and 3 and b) to the allelic distribution of SNP38 detected in the F3H encoding gene. $\perp=$ minimum values, $T=$ maximum values, boxes are 0.25 to 0.75 quartiles including $-=$ median. 
and row number. Most of the developed pyrosequencing markers are applicable for high-throughput genotyping of barley varieties. Several significant associations of the investigated candidate genes with kernel and malting quality traits were detected. Some of the derived SNPmarkers can serve as diagnostic tool for marker-assisted selection in breeding programs to achieve new high quality malting varieties.

\section{Methods}

\section{Plant material and DNA extraction}

A set of 16 diverse reference genotypes including the mapping parent Steptoe $\times$ Morex was used for resequencing and SNP-detection in five candidate genes from the phenylpropanoid pathway. Additionally, 190 barley varieties of European origin (Additional file 9), consisting of 94 spring and 96 winter types were genotyped with pyrosequencing markers from selected SNPs and InDels. The seeds for growing young plantlets were supplied by various breeding companies or obtained from the Genebank of the Leibniz Institute of Plant Genetics and Crop Plant Research (IPK) at Gatersleben. Harvested leaves from 5 to 6 plants were pooled and the genomic DNA was extracted according to a modified method of Plaschke et al. [41].

\section{PCR, DNA sequencing and SNP detection}

Sequence information (mRNAs, cDNAs or ESTs) for five genes from the phenylpropanoid pathway was obtained from NCBI (www.ncbi.nlm.nih.gov/) and are shown in Table 10. All publicly available sequences were aligned with Sequencher ${ }^{\mathrm{TM}}$ Vers. 4.06 (Gene Codes Corporation, Ann Arbor, USA). From the consensus sequences of each candidate gene, primers were designed with Primer3 Vers. 0.4.0 [42] and are shown in Additional file 10. The genomic PCR-amplification was performed in $25 \mu \mathrm{l}$ volume of PCR buffer (0.01 M Tris, $0.05 \mathrm{M} \mathrm{KCl,} 1.5 \mathrm{mM} \mathrm{MgCl}_{2}$, $0.01 \%$ gelatine) and contained $100 \mathrm{ng}$ of genomic DNA, $0.2 \mathrm{mM}$ of dCTP, dGTP, dTTP, dATP, $0.2 \mu \mathrm{M}$ of each primer and $1 \mathrm{U}$ of $\mathrm{Taq}$ polymerase. After $3 \mathrm{~min}$ at $94^{\circ} \mathrm{C}$, 45 cycles were performed with $1 \mathrm{~min}$ at $94^{\circ} \mathrm{C}, 1 \mathrm{~min}$ at $55^{\circ} \mathrm{C}, 2 \mathrm{~min}$ at $72^{\circ} \mathrm{C}$ and a final extension step of $10 \mathrm{~min}$ at $72^{\circ} \mathrm{C}$. Successfully amplified gene fragments obtained for the reference genotypes were resequenced. All sequences for each gene were aligned and compared to the template reference sequence with the software Sequencher ${ }^{\mathrm{TM}}$, and SNP and InDel polymorphisms were revealed. The exact positions of 3'- and 5'-UTR, introns and exons were determined by using GeneSeqer developed by Schlueter et al. [43].

\section{Marker development}

Pyrosequencing assays were developed for high-throughput genotyping of the 190 cultivars and the segregating mapping populations. The primer combinations were designed
Table 10 Investigated genes from the phenylpropanoid pathway

\begin{tabular}{|c|c|c|}
\hline Candidate gene & $\begin{array}{l}\text { Accession } \\
\text { number (NCBI) }\end{array}$ & Reference \\
\hline \multirow{7}{*}{$\begin{array}{l}\text { Phenylalanine } \\
\text { ammonia-lyase (PAL) }\end{array}$} & AB367438 & Miyashita and Shirako [26] \\
\hline & X97313 & Kervinen et al. [25] \\
\hline & X99482 & Peltonen and Karjalainen [21] \\
\hline & X99483 & \\
\hline & Z49145 & \\
\hline & Z49146 & \\
\hline & Z49147 & \\
\hline \multirow{5}{*}{$\begin{array}{l}\text { Cinnamate } \\
\text { 4-hydroxylase (C4H) }\end{array}$} & AK250541 & Sato et al. [27] \\
\hline & NM_001051180 & Rice Annotation Project [42] \\
\hline & NM_001053349 & \\
\hline & NM_001053354 & \\
\hline & NM_001061725 & \\
\hline \multirow{2}{*}{$\begin{array}{l}\text { Chalcone } \\
\text { synthase (CHS) }\end{array}$} & Y09233 & Christensen et al. [28] \\
\hline & U43494 & Lee et al. [29] \\
\hline $\begin{array}{l}\text { Flavanone } \\
\text { 3-hydroxylase (F3H) }\end{array}$ & X58138 & Meldgaard [9] \\
\hline $\begin{array}{l}\text { Dihydoflavonol } \\
\text { reductase (DFR) }\end{array}$ & $\begin{array}{l}\text { NM_001050192 } \\
\text { Hv.23226 (69 ESTs) }\end{array}$ & Rice Annotation Project [42] \\
\hline
\end{tabular}

$\mathrm{NCBI}$ accession numbers for the template sequences used for the genomic primer design are given.

with the PSQ Assay Design Software Version 1.0.6) provided by Biotage (Uppsala, Sweden) and are summarized in Additional file 10. The PCR-reactions with labeled biotin primers were performed in a $35 \mu \mathrm{l}$ reaction volume with an annealing temperature of $58^{\circ} \mathrm{C}$. All pyrosequencing assays were carried out according to the manufacturer's standard protocols using a pyrosequencer PSQ HS 96 from Biotage AB (Uppsala, Sweden). The analyzed SNP- and InDel-data were scored with the manufacturer's software.

CAPS marker development was performed using the program SNP2CAPS by Thiel et al. [44]. The digestions were carried out in $20 \mu \mathrm{l}$ reaction volumes with $15 \mu \mathrm{l}$ of PCR amplification product, $2 \mu \mathrm{l} 10 \times$ buffer and $2 \mathrm{U}$ restriction enzyme. All used restriction enzymes are summarized in Additional file 11.

\section{Mapping}

All SNP-markers found to be polymorphic either between the mapping parents Steptoe x Morex or Morex x Barke were tested on each double haploid (DH) mapping population. The Steptoe $\mathrm{x}$ Morex population consisted of a set of 77 double haploid lines. Linkage maps were constructed using the software MapMaker 2.0 [45]. Genetic distances were calculated by applying the Kosambi function [46]. The segregating population of Morex $\mathrm{x}$ Barke was kindly provided by Nils Stein (Leibniz Institute of Plant Genetics and Crop Plant Research, Gatersleben, Germany) and 
consisted of $93 \mathrm{DH}$ lines. Calculation was performed using JoinMap Software [47] based on a set of DArT and SNP markers [31,32].

For anchoring the investigated genes on the physical map, a blastN of the PCR-derived sequences was conducted by using the IPK BLAST server (http://webblast.ipk-gatersleben. de/barley/) on the database assembly_WGSMorex and in case of fragment GM287 on assembly_WGSBowman.

\section{Association studies}

Association studies were performed using the TASSEL software, vers. 2.1.1 developed by Bradbury et al. [48]. Three linear models were applied taking either principal components (PCA), kinship (K) and/or population structure $(\mathrm{Q})$ into account.

The population structure applied in the GLM was implemented as a Q-matrix reflecting the relative assignments of 22 random SSRs [49] to five subgroups. The genetic relationship or kinship was determined by SPAGeDi [50] applying the Ritland [51] coefficient using 22 random SSR markers. The kinship information was implemented in the MLM [36]. All calculations were performed as described previously [21]. The threshold for Bonferroni correction for multiple testing was calculated for each investigated gene separately by dividing $\mathrm{P}<0.01$ with the number of SNPs or haplotypes of the respective gene.

All investigations were carried out using SNP and InDel markers or by combining all marker data in haplotypes for each gene applying on a set of 190 European barley accessions that reflect 96 winter and 94 spring cultivars. Phenotypic values considered for this candidate gene association approach were derived from the database MetaBrew [52]. The following grain and malting quality parameters were considered: kernel yield [dt/ha], kernel formation [1-9], thousand grain weight $[\mathrm{g}]$, kernel raw protein [\%], raw protein in malt [\%], $\mathrm{pH}$, sieve fraction [\%], hectolitre weight $[\mathrm{kg}]$, brabender $[\mathrm{HE}]$, diastatic power [WK], final attenuation [\%], fermentable extract [\%], malt extract [\%], color [EBC], friability [\%], glassiness [\%], soluble nitrogen $[\mathrm{mg} / 100 \mathrm{~g}$ dry malt], malting quality index [MQI], malt extract [\%], viscosity [mPas], saccharification VZ45 [\%]. These data were published from various German state trials in different years, at different locations including variable sets of varieties per trial and year. Each trait was covered by $2-103$ single entries per variety (Additional file 12). Outliers deviating more than $20 \%$ from the mean were discarded. Mean values for each trait/variety combination were calculated over all available single entries (Additional file 13). Only mean values based on at least 20 single entries out of the total varietal set were taken into account. Due to availability of phenotypic data only up to 185 varieties were used for association analysis of the individual traits (Additional file 13).

\section{Additional files}

\begin{abstract}
Additional file 1: SNPs detected within 16 reference genotypes for the phenylalanine ammonia-lyase (PAL) gene fragment PAL_1.

Additional file 2: SNPs detected within 16 reference genotypes for the phenylalanine ammonia-lyase $(P A L)$ gene fragment PAL_2.

Additional file 3: Genetic structure of the resequenced fragments $\mathrm{C} 4 \mathrm{H} \_1$ and $\mathrm{C} 4 \mathrm{H} \_4$ from the cinnamate 4-hydroxylase $(\mathrm{C} 4 \mathrm{H})$ encoding gene. Double lines indicate UTR regions, single lines indicate no sequenced regions. Violet - CAPS marker and high-throughput SNP marker, green - high-throughput SNP marker.
\end{abstract}

Additional file 4: Positioning of the chalcone synthase (CHS) resequenced gene fragments GM_293 and GM_290, CHS_1, CHS_2 and CHS_3 in relation to CDNA Y09233. Polymorphisms were only detected in the large fragments GM_290 and GM_293. Green - high-throughput SNP marker.

Additional file 5: Detected SNPs and their resulting haplotypes within 16 reference genotypes for the chalcone synthase (CHS) gene fragment GM_293.

Additional file 6: Detected SNPs within 16 reference genotypes for the chalcone synthase (CHS) gene fragment GM_287. Four different haplotypes were identified.

Additional file 7: Genetic structure of dihydoflavonol reductase (DFR) according to Kristiansen and Rohde [30]. Primer development for resequencing was performed using sequence information of EST contig Hv.23226. Light grey boxes represent exons and double lines between exons indicate the introns. UTRs are also marked by doubled lines. Green - high-throughput SNP marker, violet - CAPS marker and high-throughput SNP marker.

Additional file 8: Marker-trait-associations of SNP polymorphisms and haplotypes found in 190 European barley cultivars and selected kernel and malting quality parameters for cinnamate 4-hydroxylase $(\mathrm{C} 4 \mathrm{H})$, flavanone 3-hydroxylase $(\mathrm{F} 3 \mathrm{H})$, dihydoflavonol reductase $(D F R)$, chalcon synthase $(C H S)$ and phenylalanine ammonia-lyase (PAL). Considered statistical models: 1. Mixed linear model (MLM) with principal component analysis (PCA), 2. MLM with kinship, 3. General linear model (GLM) with population structure. Significant at ${ }^{*} p<0.05,{ }^{* *} p<0.01,{ }^{* *} p<0.001$, n.s. not significant. Additional file 9: List of investigated 190 barley varieties. Additional file 10: List of primers used for PCR amplification and sequencing.

Additional file 11: Used restriction enzymes for CAPS marker development and reaction conditions.

Additional file 12: Trait statistics of single phenotypic values across 185 varieties (before elimination of outliers) for 22 traits.

Additional file 13: Phenotypic data used for association analysis (mean values for each trait/variety combination after elimination of outliers).

\section{Competing interests}

The authors declare that they have no competing interests.

\section{Authors' contributions}

IEM and MSR conceived and supervised the project. MP conducted the scientific research, performed data analysis and drafted the manuscript. SW helped with data analysis. All authors read and approved the manuscript.

\section{Acknowledgements}

We thank Nils Stein for supplying the mapping populations and the data framework and also Susanne König for performing the candidate gene re-sequencing with the 16 reference genotypes.

Received: 11 December 2012 Accepted: 25 September 2013 Published: 2 October 2013 


\section{References}

1. FAOSTAT Database on Agriculture. [http://faostat.fao.org/site/339/default.aspx]

2. Ullrich SE: Significance, Adaption, Production, and Trade of Barley. In Barley: Production, Improvement, and Uses. Edited by Ullrich SE. Chichester, West Sussex, UK: Wiley-Blackwell; 2011:3-13.

3. Holtekjølen AK, Kinitz C, Knutsen SH: Flavanol and Bound Phenolic Acid Contents in Different Barley Varieties. J Agric Food Chem 2006, 54(6):2253-2260.

4. Gamel T, Abdel-Aal E: Phenolic acids and antioxidant properties of barley wholegrain and pearling fractions. Agricultural and Food Science 2012, 21:118-131.

5. Dvoráková M, Guido LF, Dostálek P, Skulilová Z, Moreira MM, Barros AA: Antioxidant properties of free, soluble ester and insoluble-bound phenolic compounds in different barley varieties and corresponding malts. J Inst Brew 2008, 114(1):27-33.

6. Gupta M, Abu-Ghannam N, Gallaghar E: Barley for brewing: characteristic changes during malting, brewing and applications of its by-products. Comprehensive Reviews in Food Science and Food Safety 2010, 9(3):318-328.

7. Labib S: Ex-vivo-Studien zum intestinalen Metabolismus von Flavonoiden. Würzburg: University of Würzburg; 2006

8. Winkel-Shirley B: Flavonoid biosynthesis. A colorful model for genetics, biochemistry, cell biology, and biotechnology. Plant Physiol 2001, 126(2):485-493.

9. Meldgaard M: Expression of chalcone synthase, dihydroflavonol reductase, and flavanone-3-hydroxylase in mutants of barley deficient in anthocyanin and proanthocyanidin biosynthesis. TAG Theor Appl Genet 1992, 83(6):695-706.

10. Andersen $\varnothing \mathrm{M}$, Jordheim M: Anthocyanin. In eLS. New Jersey: John Wiley \& Sons, Ltd; 2010.

11. Khlestkina EK, Röder MS, Salina EA: Relationship between homoeologous regulatory and structural genes in allopolyploid genome - a case study in bread wheat. BMC Plant Biology 2008, 8:88.

12. Butelli E, Titta L, Giorgio M, Mock HP, Matros A, Peterek S, Schijlen E, Hall RD, Bovy AG, Luo J, et al: Enrichment of tomato fruit with health-promoting anthocyanins by expression of select transcription factors. Nat Biotechnol 2008, 26(11):1301-1308.

13. Jende-Strid B: Gene-enzyme relations in the pathway of flavonoid biosynthesis in barley. Theor Appl Genet 1991, 81(5):668-674.

14. Narziß L, Back W: Die Bierbrauerei Band I: Die Technologie der Malzbereitung, vol. 7. Stuttgart: Ferdinand Enke Verlag, Stuttgart; 1999.

15. Cockram J, White J, Leigh FJ, Lea VJ, Chiapparino E, Laurie DA, Mackay IJ, Powell W, O'Sullivan DM: Association mapping of partitioning loci in barley. BMC Genet 2008, 9:16.

16. Haseneyer G, Ravel C, Dardevet M, Balfourier F, Sourdille P, Charmet G, Brunel D, Sauer S, Geiger H, Graner A: High level of conservation between genes coding for the GAMYB transcription factor in barley (Hordeum vulgare L.) and bread wheat (Triticum aestivum L.) collections. TAG Theor Appl Genet 2008, 117(3):321-331.

17. Haseneyer G, Stracke S, Piepho H-P, Sauer S, Geiger H, Graner A: DNA polymorphisms and haplotype patterns of transcription factors involved in barley endosperm development are associated with key agronomic traits. BMC Plant Biol 2010, 10(1):5

18. Stracke S, Haseneyer G, Veyrieras J-B, Geiger H, Sauer S, Graner A, Piepho $\mathrm{H}-\mathrm{P}$ : Association mapping reveals gene action and interactions in the determination of flowering time in barley. TAG Theor Appl Genet 2009, 118(2):259-273.

19. Matthies IE, Weise MS, Förster J, Röder M: Association mapping and marker development of the candidate genes $(1 \rightarrow 3),(1 \rightarrow 4)-\beta$-d-Glucan-4glucanohydrolase and $(1 \rightarrow 4)-\beta$-Xylan-endohydrolase 1 for malting quality in barley. Euphytica 2009, 17(1-2):109-122.

20. Matthies IE, Weise S, Röder MS: Association of haplotype diversity in the alpha-amylase gene amy1 with malting quality parameters in barley. $\mathrm{Mol}$ Breed 2009, 23(1):139-152.

21. Matthies IE, Sharma S, Weise S, Röder MS: Sequence variation in the barley genes encoding sucrose synthase I and sucrose phosphate synthase II, and its association with variation in grain traits and malting quality. Euphytica 2012, 184(1):73-83.

22. Bundock PC, Henry RJ: Single nucleotide polymorphism, haplotype diversity and recombination in the Isa gene of barley. TAG Theor Appl Genet 2004, 109(3):543-551.

23. Kanazin V, Talbert H, See D, DeCamp P, Nevo E, Blake T: Discovery and assay of single-nucleotide polymorphisms in barley (Hordeum vulgare). Plant Mol Biol 2002, 48(5-6):529-537.
24. Rostoks N, Mudie S, Cardle L, Russell J, Ramsay L, Booth A, Svensson JT, Wanamaker SI, Walia H, Rodriguez EM, et al: Genome-wide SNP discovery and linkage analysis in barley based on genes responsive to abiotic stress. MGG 2005, 274(5):515-527.

25. Kervinen T, Peltonen S, Utriainen M, Kangasjarvi J, Teeri TH, Karjalainen R: Cloning and characterization of CDNA clones encoding phenylalanine ammonia-lyase in barley. Plant Sci 1997, 123(1):143-150.

26. Miyashita S, Shirako Y: Chromosomal integration of a binding domain:bait gene into yeast enhances detection in the two-hybrid system. J Microbiol Methods 2008, 73(2):179-184.

27. Sato K, Shin-I T, Seki M, Shinozaki K, Yoshida H, Takeda K, Yamazaki Y, Conte M, Kohara Y: Development of 5006 Full-Length CDNAs in Barley: A Tool for Accessing Cereal Genomics Resources. DNA Res 2009, 16(2):81-89.

28. Christensen AB, Gregersen PL, Schroder J, Collinge DB: A chalcone synthase with an unusual substrate preference is expressed in barley leaves in response to UV light and pathogen attack. Plant Mol Biol 1998, 37(5):849-857.

29. Lee J, Parthier B, Löbler M: Jasmonate signalling can be uncoupled from abscisic acid signalling in barley: identification of jasmonate-regulated transcripts which are not induced by abscisic acid. Planta 1996, 199(4):625-632

30. Nyegaard Kristiansen K, Rohde W: Structure of the Hordeum vulgare gene encoding dihydroflavonol-4-reductase and molecular analysis of ant18 mutants blocked in flavonoid synthesis. Mol Gen Genet MGG 1991, 230(1-2):49-59.

31. Wenzl P, Li H, Carling J, Zhou M, Raman H, Paul E, Hearnden P, Maier C, Xia $L$, Caig V, et al: A high-density consensus map of barley linking DArT markers to SSR, RFLP and STS loci and agricultural traits. BMC Genomics 2006, 7(1):206

32. Close T, Bhat P, Lonardi S, Wu Y, Rostoks N, Ramsay L, Druka A, Stein N, Svensson J, Wanamaker S, et al: Development and implementation of high-throughput SNP genotyping in barley. BMC Genomics 2009, 10(1):582.

33. Khlestkina EK, Salina EA, Matthies IE, Leonova IN, Börner A, Röder MS: Comparative molecular marker-based genetic mapping of flavanone 3-hydroxylase genes in wheat, rye and barley. Euphytica 2011, 179(2):333-341.

34. Consortium IBGS: A physical, genetic and functional sequence assembly of the barley genome. Nature 2012, 491(7426):711-716.

35. Pecchioni N, Vale G, Toubia-Rahme H, Faccioli P, Terzi V, Delogu G: Barley - pyrenophora graminea interaction: QTL analysis and gene mapping. Plant Breed 1999, 118(1):29-35.

36. Matthies IE, Hintum T, Weise S, Röder MS: Population structure revealed by different marker types (SSR or DArT) has an impact on the results of genome-wide association mapping in European barley cultivars. Mol Breed 2012, 30(2):951-966.

37. Herz M, Nickl U, Fink K, Henkelmann G: Faktorielle Sortenversuche Gerste - Brauqualität und Kornphysikalische Untersuchungen. Freising: Bayerische Landesanstalt für Landwirtschaft, Institut für Pflanzenbau und Pflanzenzüchtung; 2006.

38. Beattie AD, Edney MJ, Scoles GJ, Rossnagel BG: Association mapping of malting quality data from Western Canadian two-row barley cooperative trials. Crop Sci 2010, 50(5):1649-1663.

39. Szücs P, Blake VC, Bhat PR, Chao S, Close TJ, Cuesta-Marcos A, Muehlbauer GJ, Ramsay L, Waugh R, Hayes PM: An integrated resource for barley linkage map and malting quality OTL alignment. Plant Genome 2009, 2(2):134-140.

40. Marquez-Cedillo LA, Hayes PM, Jones BL, Kleinhofs A, Legge WG, Rossnagel BG, Sato K, Ullrich SE, Wesenberg DM: North American barley genome mapping $\mathrm{P}:$ QTL analysis of malting quality in barley based on the doubled-haploid progeny of two elite North American varieties representing different germplasm groups. Theor Appl Genet 2000, 101(1-2):173-184.

41. Plaschke J, Ganal MW, Röder MS: Detection of genetic diversity in closely related bread wheat using microsatellite markers. Theor Appl Genet 1995, 91(6-7):1001-1007.

42. Rozen S, Skaletsky H: Primer3 on the WWW for general users and for biologist programmers. In Bioinformatics Methods and Protocols. Edited by Misener S, Krawetz S. Totowa, New Jersey: Humana Press; 1999:365-386. vol. 132 of Methods in Molecular Biology.

43. Schlueter SD, Dong QF, Brendel V: GeneSeqer@PlantGDB: gene structure prediction in plant genomes. Nucleic Acids Res 2003, 31(13):3597-3600.

44. Thiel T, Kota R, Grosse I, Stein N, Graner A: SNP2CAPS: a SNP and INDEL analysis tool for CAPS marker development. Nucleic Acids Res 2004, 32(1):e5. 
45. Lander ES, Green P, Abrahamson J, Barlow A, Daly MJ, Lincoln SE, Newburg L: MAPMAKER: An interactive computer package for constructing primary genetic linkage maps of experimental and natural populations. Genomics 1987, 1(2):174-181.

46. Kosambi D: The estimation of map distances from recombination values. Ann Eugen 1944, 12:172-175.

47. Van Ooijen JW: JoinMap, 4 Software for the Calculation of Genetic Linkage Maps in Experimental Populations. Wageningen, Netherlands; 2006.

48. Bradbury PJ, Zhang Z, Kroon DE, Casstevens TM, Ramdoss Y, Buckler ES: TASSEL: software for association mapping of complex traits in diverse samples. Bioinformatics 2007, 23(19):2633-2635.

49. Malysheva-Otto LV, Ganal MW, Röder MS: Analysis of molecular diversity, population structure and linkage disequilibrium in a worldwide survey of cultivated barley germplasm (Hordeum vulgare L.). BMC Genetics 2006, 7:6.

50. Hardy OJ, Vekemans X: SPAGeDi: a versatile computer program to analyse spatial genetic structure at the individual or population levels. Mol Ecol Notes 2002, 2(4):618-620.

51. Ritland K: Estimators for pairwise relatedness and individual inbreeding coefficients. Genet Res 1996, 67(02):175-185.

52. Weise S, Scholz U, Röder MS, Matthies IE: MetaBrew: a comprehensive database of malting quality traits in brewing barley. Barley Genetics Newsletter 2009, 39:1-4.

doi:10.1186/1471-2156-14-97

Cite this article as: Peukert et al: Development of SNP markers for genes of the phenylpropanoid pathway and their association to kernel and malting traits in barley. BMC Genetics 2013 14:97.

\section{Submit your next manuscript to BioMed Central and take full advantage of:}

- Convenient online submission

- Thorough peer review

- No space constraints or color figure charges

- Immediate publication on acceptance

- Inclusion in PubMed, CAS, Scopus and Google Scholar

- Research which is freely available for redistribution 